\title{
A emergência de leitura de frases compostas por números e palavras de ensino ${ }^{1}$
}

\author{
José Gonçalves Medeiros \\ Igor Schütz dos Santos \\ Adriana Garcia Stefani \\ Vinicius Linhares Martins \\ Universidade Federal de Santa Catarina
}

\begin{abstract}
RESUMO
O presente artigo mostra um procedimento de ensino de leitura de palavras e de unidades numéricas. Desse modo, tendo sido ensinado separadamente o comportamento de ler palavras e números, estas classes de estímulos foram apresentadas juntas formando pequenas frases. Participaram desse estudo 13 crianças da primeira série, da rede pública estadual, que não apresentavam o repertório de ler e o de identificar ${ }^{2}$ números. O grupo foi composto por crianças do sexo masculino e feminino, cujas idades variavam entre 6 e 7 anos. O ler e o escrever, bem como identificar números, foram ensinados por meio de um procedimento de discriminação condicional por exclusão das palavras e números conhecidos. Os dados mostram que todos os participantes, exceto dois (P1 e P2) aprenderam a ler e escrever as palavras de ensino e a identificar números. Nas etapas de testes, estabeleceram, também, as equivalências $\mathrm{BC} / \mathrm{CB}$, leram as palavras impressas correspondentes corretamente e frente a palavras impressas, identificaram as figuras correspondentes corretamente. Na situação de teste, leram as frases compostas por palavras e números. Os dados são discutidos mostrando que o ler e escrever palavras são equivalentes ao identificar números e que a seqüência de ensino das unidades independentes palavras/números facilitou a emergência de leitura de frases.

Palavras-chave: leitura de frases; identificar números; equivalência palavra-número.
\end{abstract}

\section{ABSTRACT}

\section{Emergency of sentences reading composed by numerals and taught words}

This article presents a procedure to teach how to read and write words and numerical units. Thus, after teaching how to read words and numerals separately, such classes of stimuli were presented together forming short sentences. Thirteen first grade children from public schools, who did not present the repertories of reading words and identifying numerals previously, took part of this study. Male end female children aged from six to seven years old formed the group. Reading and writing, as well as the activity of identifying numerals were taught through a conditional discrimination procedure, by means of excluding words and numerals that they already knew. The data show that, except for two participants (P1 e P2), all of the children learned how to read and write the taught words and how to identify the taught numerals. During some tests, they also established BC/CB equivalence relations. They read the corresponding words and numerals correctly, and identified the pictures before the corresponding printed words. During the tests they also read sentences with words and numerals. Data are here discussed, and show that reading and writing words are equivalent activities to identifying numerals, and that the teaching sequence of the independent units of words/numerals facilitated the sentences reading emergence.

Keywords: sentence reading; numerals identification; word-numeral equivalence.

Os estudos de equivalência de estímulos têm demonstrado a possibilidade de ensinar os comportamentos de ler e escrever palavras independentemente dos comportamentos de ler e escrever números (algarismos arábicos: $0,1,2,3 \ldots n$; numerais cardinais: zero, um, dois, três ... $n$; numerais ordinais: primeiro, segundo, terceiro ... n). Isto se deve, talvez, ao fato de que para ler e escrever números, em especial os numerais cardinais e ordinais, o participante, nesses casos, teria que ler palavras compostas por ditongos e encontros consonantais. Assim, neste artigo, descrevese o processo de aquisição dos comportamentos de ler 
e escrever palavras e o de ler números (Monteiro e Medeiros, 2002), apresentados alternadamente e fundamentado nos estudos de equivalência de estímulos (Dixon, 1977; Sidman, 1971; Souza \& de Rose, 1997).

As investigações iniciais em aquisição de leitura e escrita, inaugurando uma nova área de pesquisa, ficaram conhecidas como equivalência de estímulos (d’Oliveira \& Matos, 1993; Medeiros, Monteiro \& Silva, 1997; Melchiori, Sousa \& de Rose, 1992; Sidman, 1971; Sidman \& Cresson, 1973). No estudo de Sidman de 1971, realizado com adolescentes com deficiência mental, os sujeitos já eram capazes, antes do início do experimento, de: a) nomear as figuras que lhes foram apresentadas; b) foram capazes de escolher as figuras correspondentes a palavras ditadas e c) foram capazes de selecionar uma palavra impressa frente a uma palavra ditada. Em decorrência do ensino, os adolescentes foram capazes de emparelhar palavras impressas com suas respectivas figuras (CB) e a emparelhar figuras com seus respectivos nomes (BC) e de ler (D) sob controle do estímulo impresso C (relação CD). Os resultados obtidos por Sidman sugerem que se uma pessoa aprende, por meio do procedimento de discriminação condicional, as relações entre palavra falada e figura (AB), entre palavra falada e palavra impressa (AC), as relações CB (entre palavra impressa e figura), BC (entre figura e palavra impressa) e CD (entre palavra impressa e palavra falada pelo sujeito) podem emergir sem que elas tenham sido diretamente ensinadas. Nesse sentido, o paradigma de equivalência de estímulos tem sido bastante utilizado, à medida que oferece bases para uma análise comportamental de comportamentos emergentes (Mackay, 1985; Sidman, 1990).

A ênfase nas unidades textuais mínimas tem-se constituído como condição importante para a ocorrência de comportamentos emergentes. Esta linha de pesquisa teve prosseguimento com alguns estudos realizados no Brasil (Bastos, 2004; de Rose, Rossito, Souza \& Rose, 1992; d'Oliveira \& Matos, 1993; Hanna, Souza, de Rose e cols., 1993; Matos, Hübner, Peres \& Malheiros, 1997; Matos, Hubner, Serra, Basaglia \& Avanzi, 2002; Medeiros, Fernandes, Pimentel \& Simone, 2004). As unidades textuais mínimas tem tido função importante também na aquisição de leitura generalizada, cuja ocorrência foi demonstrada nos estudos de de Rose e cols. (1992), Dixon (1977), d'Oliveira e Matos (1993), Matos e cols. (1997), Melchiori e cols. (1992) e Souza e de Rose (1997). Para d'Oliveira e Matos (1993), o controle pelas unidades mínimas apresentou-se melhor com a variação sistemática das sílabas, "ora como primeira sílaba, ora como segunda sílaba” (p. 105). No estudo posterior, em 1997, Matos e cols. novamente ensinaram palavras com as sílabas sistematicamente variadas, "como ocorre no conjunto das palavras bolo, lobo, boca e cabo" (p. 50), com crianças não alfabetizadas. Com esse procedimento, os autores não só aumentaram o controle de estímulos como também diminuíram a variabilidade de desempenho. Estudo semelhante com variação das sílabas, ora na primeira, ora na segunda posição foi realizado por Medeiros e cols. (2004), com níveis de generalização próximos de 100 por cento. $\mathrm{Na}$ organização das palavras de generalização, estas foram montadas com as sílabas das palavras de ensino. Como, na etapa de ensino, elas foram reforçadas em diferentes posições, é provável que a alta porcentagem de leitura correta dessas palavras possa ser explicada pelo uso dessa estratégia, conforme defendido por Matos e cols. (1997) e por Medeiros e cols. (2004).

De modo semelhante aos estudos de ensino de leitura, o ensino do conceito de números (Carmo, 1997, 2002; Drachenberger, 1973, 1990; Monteiro \& Medeiros, 2002) tem ocupado, também, as páginas dos periódicos, porém em número bem mais reduzido. Um dos primeiros pesquisadores no Brasil a ensinar o conceito de número a crianças pré-escolares foi Drachenberger $(1973,1990)$ por meio do procedimento de escolha segundo o modelo, tendo por referência um aumento progressivo de dificuldades nas tarefas, no sentido de aumentar o número de acertos durante o processo de aprendizagem. Os trabalhos de Carmo (1997, 2002), Gast, VanBiervliet e Spradlin (1979), Green (1992), Kahhale (1993), Kennedy e Serna (1995) e Prado (1995) mostram também a importância do ensino desse conceito: um ensino que garanta a abstração (generalização) a partir de relações entre referenciais concretos. Em estudo recente, Medeiros, Vettorazzi, Kliemann, Kurban e Matheus (2007) ensinaram separadamente palavras e números e, em situação de teste, apresentaram palavras e números agrupados ${ }^{3}$, com emergência de leitura dessas novas configurações em praticamente todos os participantes.

A análise do processo de leitura (relação CD) dessas unidades agrupadas mostra que o conteúdo ensinado possui elementos comuns. Os estímulos usados $(1,2,3,4,5 \ldots$ etc.) nos procedimentos de ler números foram ensinados por meio da associação entre um número falado [“um” (A)] com a figura correspondente [1 (B)] e com palavra escrita [um (C)]. Desse modo, o ensino de um elemento da categoria ("um” 
[A], por exemplo) associado com a figura correspondente (1 [B], por exemplo) e "um" (A) associado com a palavra escrita correspondente (um [C]) deveria garantir, segundo a literatura da área, a equivalência entre $\underline{u m}$ (C) e $\underline{1}$ (B), assim como a reversibilidade, ou seja, 1 (B) e um (C). Portanto, ao ensinarmos a leitura de uma determinada palavra ("bola", por exemplo) independente do ensino de um dos números (3, três, etc.) e se apresentarmos esses estímulos juntos, constituindo um nova unidade de leitura, deveria emergir a leitura dessa nova unidade, em que o sujeito leria, sem qualquer treino, a expressão "três bolas", entre outras combinações.

As possibilidades de ampliação das classes emergentes de leitura de unidades agrupadas ensinadas independentemente, um tempo menor para o ensino dessas classes e uma integração mais consistente entre os conteúdos ensinados para as crianças que iniciam a educação de primeiro grau são aspectos a serem descritos e discutidos nas secções que se seguem. Deste modo, pretende-se, com este projeto, responder à pergunta de pesquisa: os comportamentos de ler e escrever, ensinados independentemente do ensino do comportamento de ler números e numerais, controlaria a leitura de ambos os repertórios quando apresentados juntos numa situação de teste?

\section{MÉTODO}

\section{Participantes}

Participaram desse estudo 13 crianças, agora denominadas de participantes ( $\mathrm{P}$ ou Ps), da primeira série que não apresentavam o repertório de leitura e o de identificação de números ${ }^{4}$. O grupo foi composto por crianças do sexo masculino e feminino, cujas idades variavam entre 6 e 7 anos. São alunos de uma escola da rede pública estadual, localizada em Florianópolis, SC.

\section{Seleção dos Participantes}

Um teste inicial de leitura de palavras, de números, numerais e de quantidades (ver Tabela 1) foi aplicado com o objetivo de avaliar o repertório inicial dos Ps por (foram selecionados os Ps com porcentagens de leitura correta entre 0 e 20 por cento). Apenas um $\mathrm{P}$ foi escolhido com porcentagem acima desse intervalo: P4 que leu 26 de 42 palavras do teste inicial (61,9\%), no entanto, não identificava números. Quantidade de bolinhas também fez parte do teste inicial, mas não foi utilizado como critério de escolha porque a porcentagem de acertos já era elevada (os Ps 1, 3, 7, 8, 10 e 11 apresentaram 100 por cento de acerto e os demais em torno de 80 por cento, em média, de acertos ${ }^{5}$ ). O teste foi repetido ao final do procedimento para avaliar os efeitos do procedimento.

TABELA 1

Seqüência de Apresentação, Tipo e Número de Apresentações de Estímulos nos Testes Inicial e Final

\begin{tabular}{|c|c|c|}
\hline \multicolumn{3}{|c|}{ Estímulos } \\
\hline Seqüência de apresentação & Tipos & Quantidade \\
\hline a) Números & $1,2,3,4,5,6,7,8,9$ & 9 \\
\hline b) Numerais & um, uma, dois, duas, três, quatro, cinco, seis, sete, oito, nove & 11 \\
\hline c) Quantidades & $0,00,000,0000,00000,000000,0000000,00000000,000000000$ & 9 \\
\hline d) Palavras ${ }^{a}$ & $\begin{array}{l}\text { cama, mago, foca, boca, calo, lobo, bala, lago, gota, doce, cela, lata, } \\
\text { mico, copo, pote, fita, taco, cola, [macaco, camisa, caneca, calça, açúcar, } \\
\text { cesta, girafa, barraca, colar, ninho, minhoca, lenha, anjo, bandeira, } \\
\text { balança, palhaço, abelha, velho, queijo, coqueiro, leque, soldado, pastel, } \\
\text { pulseira]. }\end{array}$ & 42 \\
\hline
\end{tabular}

a A leitura de 18 palavras foi ensinada (de cama até cola). As demais palavras (entre colchetes e itálicas) foram apresentadas apenas nos Testes Iniciais e Finais.

\section{Local}

O procedimento experimental foi realizado no Laboratório de Informática da Escola, onde se encontram instalados os computadores para uso regular dos alu- nos. Desses, em três foi instalado o software Mestre@ para o ensino de leitura e identificação de números aos Ps do procedimento. A sala possui cortinas e janelas que possibilitam a visão de um pátio externo e 
de uma avenida. A sala também era utilizada por alunos que não participavam do procedimento.

\section{Material e Equipamento}

Foram utilizados três computadores, com recurso multimídia, placa de som, alto-falantes Labtec LCS 150, CD-ROM, e o software Mestre@ (Goyos \& Almeida, 1996). Os computadores e os periféricos estão instalados sobre uma mesa, em frente da qual se sentava o P. Fones de ouvido também foram utilizados para evitar a interferência de estímulos auditivos provenientes dos outros programas que estavam funcionando simultaneamente.

\section{Procedimento}

Escolha de acordo com o modelo foi o procedimento usado para expandir gradualmente, ao longo de uma seqüência de passos, o repertório de pareamentos entre estímulos-modelos e estímulos de comparação. O programa envolveu também a inserção de testes iniciais e finais, pré e pós-testes, testes de equivalência de palavras, teste de agrupamento (números/numerais mais palavras) e testes de equivalência de agrupamento, como pode ser visto na Tabela 2.

TABELA 2

Seqüência das Fases e Etapas do Procedimento, Especificando as Palavras, Números e Numerais de Ensino e de Teste, Bem Como as Palavras de Generalização. As linhas em tons cinza indicam fases de teste.

\begin{tabular}{|c|c|c|}
\hline SEQÜÊNCIA DO PROCEDIMENTO & Palavras, números e numerais & Palavras de generalização \\
\hline TESTE INICIAL & Relacionadas na Tabela 1 & \\
\hline L.B. DAS PALAVRAS INICIAIS & cama, mago, foca & \\
\hline EXC. 1: NUM. E NUMERAIS & 1, 2, 3, um, dois, três & \\
\hline Exc. 1: palavras & boca, calo, lobo & maca, goma, fogo \\
\hline Equivalência 1 (BC/CB) & cama, mago, foca, boca, calo lobo & \\
\hline $\begin{array}{l}\text { Agrupamento } 1(C D) \text { : } \\
\text { números/numerais e palavras. }\end{array}$ & $\begin{array}{l}2 \text { camas, } 3 \text { magos, uma foca, duas bocas, três calos, } 1 \text { lobo, uma cama, dois } \\
\text { magos, três focas, } 1 \text { boca, } 2 \text { calos, } 3 \text { lobos, três camas, } 1 \text { mago, } 2 \text { focas, } \\
3 \text { bocas, um calo, dois lobos }\end{array}$ & $\begin{array}{l}\text { Palavras de ensino no } \\
\text { plural e os numerais uma e } \\
\text { duas. }\end{array}$ \\
\hline $\begin{array}{l}\text { Equivalência de Agrupamento } 1 \\
\text { (BC/CB) }\end{array}$ & $\begin{array}{l}\text { três bocas, dois calos, um mago, três lobos, duas camas, uma foca, uma boca, } \\
\text { três calos, dois magos, três lobos, uma cama, duas focas }\end{array}$ & \\
\hline EXC. 2: PALAVRAS & bala, lago, gota & bolo, cabo, bobo \\
\hline EXC. 2: NUM. E NUMERAIS & $4,5,6$, quatro, cinco, seis & \\
\hline EXC. 3: PALAVRAS & doce, cela, lata & bago, bata, gola \\
\hline Equivalência 2 (BC/CB) & bala, lago, gota, doce, cela, lata & \\
\hline $\begin{array}{l}\text { Agrupamento } 2(C D) \text { : } \\
\text { números/numerais e palavras. }\end{array}$ & $\begin{array}{l}5 \text { balas, seis lagos, quatro gotas, cinco celas, seis doces, } 4 \text { latas, quatro balas, } \\
\text { cinco lagos, seis gotas, } 4 \text { celas, } 5 \text { doces, } 6 \text { latas, seis balas, } 4 \text { lagos, } 5 \text { gotas, } \\
6 \text { celas, quatro doces, cinco latas }\end{array}$ & $\begin{array}{l}\text { Palavras de ensino no } \\
\text { plural. }\end{array}$ \\
\hline $\begin{array}{l}\text { Equivalência de Agrupamento } 2 \\
\text { (BC/CB) }\end{array}$ & $\begin{array}{l}\text { cinco balas, cinco lagos, seis doces, seis gotas, seis latas, quatro celas, quatro } \\
\text { balas, seis lagos, quatro doces, cinco gotas, quatro, latas, seis celas }\end{array}$ & \\
\hline EXC. 4: PALAVRAS & mico, copo, pote & lado, cedo, tala \\
\hline EXC. 3: NUM. E NUMERAIS & $7,8,9$, sete, oito, nove & \\
\hline EXC. 5: PALAVRAS & Fita, taco, cola & teco, comi, tela \\
\hline Equivalência 3 (BC/CB) & mico, copo, pote, fita, taco, cola & \\
\hline $\begin{array}{l}\text { Agrupamento } 3(C D) \text { : } \\
\text { números/numerais e palavras. }\end{array}$ & $\begin{array}{l}8 \text { micos, } 9 \text { copos, sete potes, oito fitas, nove tacos, } 7 \text { colas, sete micos, oito } \\
\text { copos, nove potes, } 7 \text { fitas, sete tacos, oito colas, nove micos, } 7 \text { copos, } 8 \text { potes, } \\
9 \text { fitas, } 8 \text { tacos, } 9 \text { colas }\end{array}$ & $\begin{array}{l}\text { Palavras de ensino no } \\
\text { plural. }\end{array}$ \\
\hline $\begin{array}{l}\text { Equivalência de Agrupamento } 3 \\
\text { (BC/CB) }\end{array}$ & $\begin{array}{l}\text { nove micos, nove copos, oito fitas, sete potes, nove colas, sete tacos, oito } \\
\text { micos, sete copos, nove fitas, oito potes, oito colas, oito tacos }\end{array}$ & \\
\hline Teste final & Relacionadas na Tabela 1 & \\
\hline
\end{tabular}




\section{Fases de ensino de palavras e números: linha de base e exclusão}

\section{Etapa de Pré-Teste}

As fases de ensino iniciavam-se com a aplicação de um pré-teste (Pré-T) que verificava o repertório de leitura de três palavras ensinadas na exclusão anterior e de três a serem ensinadas no passo programado por meio do procedimento de exclusão. O Pré-T avaliava também a leitura de três palavras de generalização, formadas a partir das sílabas das palavras de ensino da linha de base imediatamente anterior. No caso das fases que envolviam números, o Pré-T constava apenas de três números a serem ensinados naquela etapa.

\section{Etapa de Exclusão}

Nesta etapa (Exc), leitura de palavras e números era ensinada por meio do procedimento de exclusão do estímulo conhecido. A exclusão envolveu o ensino de três palavras, três números e os respectivos numerais, com tentativas distintas para cada tipo de estímulo como pode ser visto na Tabela 3. Na apresentação dos estímulos, no caso de um estímulo modelo auditivo (A), um quadrado branco aparecia na parte superior da tela do computador. O clicar sobre o quadrado branco produzia na parte inferior da tela, o aparecimento do estímulo de comparação (podendo ser uma palavra, uma figura ou um número) correspondente ao estímulo modelo-auditivo. Tentativas corretas e incorretas eram consequenciadas nos passos onde estava ocorrendo o procedimento de ensino de novas relações, por meio de diferentes tipos de imagens animadas e expressões verbais fornecidas pelo software Mestre@ (conforme descrito em Medeiros e cols., 2004). O clicar sobre o estímulo de comparação correto produzia o aparecimento, em toda a tela, de uma das cenas de crianças brincando acompanhada da expressão verbal "perfeito" ou "muito bem" ou "é isso aí, meu" ou "excelente". Se o clicar fosse sobre o estímulo de comparação incorreto, as expressões verbais podiam ser: "Ah! Você errou!" ou "que dó, você errou!" ou "oh! oh! você errou!". Os feedbacks eram liberados pelo próprio programa de ensino e consistiam na apresentação, após cada tarefa (se correta ou incorreta), da figura de uma criança jogando basquete, pulando corda, brincando de patins e brincando de skate. Os diferentes tipos de feedback eram apresentados de forma aleatória.

\section{Etapa de montagem}

Tentativas de montagem foram também realizadas: frente à relação palavra ditada (A) (ou número/numeral) ou palavra impressa (C) (ou número/numeral), o $\mathrm{P}$ montava (F) a palavra ou número/numeral correspondente (rAF/CF), clicando com o mouse sobre as letras ${ }^{6}$, na parte inferior da tela, que compunham os estímulos modelos. Após o clique, a letra deslocava-se para a parte superior da tela, formando, então, letra a letra, a palavra ou número ou numeral modelo apresentada (A ou C). Instruções verbais do tipo "Escolha as letras para escrever a palavra clicando sobre uma delas" eram fornecidas pelo E.

\section{Etapa de Pós-Teste}

Após essa etapa, no Pós-Teste (Pós-T), leitura de palavras, de números ou de numerais ensinada na exclusão era novamente avaliada, bem como as palavras de generalização (nas exclusões que envolviam números não existiam palavras de generalização). Acertos e erros nos Pré-T e Pós-T não recebiam qualquer tipo de conseqüência experimentalmente planejada.

\section{Critério de encerramento e ou passagem para etapa posterior}

O avanço para etapa posterior dependia de critérios percentuais específicos, dependendo do tipo de estímulo e relação. Para continuar no procedimento, os Ps deveriam apresentar: (a) 100\% de acertos no PréTeste, em uma sessão, de leitura das palavras da Linha de Base anterior. Se o $\mathrm{P}$ não respondesse com este percentual de acerto, o E apresentava a Exclusão imediatamente anterior; (b) Exclusão: 91,6\% de acerto em uma sessão, na montagem das relações AF (estímulo auditivo - montagem) e na montagem das relações CF (palavra impressa - montagem); 95,2\% na nomeação das relações AB (estímulo auditivo - figura) e das relações AC (estímulo auditivo - palavra impressa) e (c) Pós-Teste: $100 \%$ de acerto, em uma sessão, das relações AC das palavras de ensino, números e numerais, conforme visto na Tabela 3, na página a seguir.

\section{Fases de Teste: de equivalência de palavras e figuras, de agrupamento e de equivalência de agrupamento}

Ao término das primeiras Linha de Base e Exclusão de palavras, de números e numerais, e tendo atingido o critério para a realização da próxima exclusão, os Ps foram submetidos aos testes como apresentados na Figura 1: A) teste de equivalência de palavras e 
figuras ( $\mathrm{rBC} / \mathrm{CB})$; B) teste de agrupamento de palavras, de números e numerais ( $\mathrm{rCD}$ ) e $\mathrm{C}$ ) teste de equivalência de agrupamento de palavras, de números e numerais ( $\mathrm{rBC} / \mathrm{CB})$. Esta seqüência de ensino de palavras, de números e numerais e de testes de equivalência, testes de agrupamento e testes de equivalência de agrupamento ocorreu sistematicamente até o final do procedimento conforme está indicado na Tabela 2 supra.
A Tabela 2 apresenta, na primeira coluna da esquerda, um esquema da seqüência do programa de ensino e de testes; na segunda coluna estão indicadas as palavras, números e numerais de ensino e testados durante o procedimento e, na terceira coluna, estão indicadas as palavras de generalização, números e numerais apresentadas aos Ps.

TABELA 3

Número de Tentativas e Critério para Mudança de Fase no Ensino (parte superior) e no Teste (parte inferior)

ETAPAS DE

\begin{tabular}{|c|c|c|c|c|c|c|c|c|c|c|c|c|c|c|}
\hline & \multicolumn{6}{|c|}{ Pré-Teste } & \multicolumn{4}{|c|}{ Exclusão } & \multicolumn{4}{|c|}{ Pós-Teste } \\
\hline FASES & $A B$ & $A C$ & $\mathrm{BC}$ & $A C$ & AF & CF & $A B$ & $A C$ & $\mathrm{AF}$ & $\mathrm{CF}$ & BC & $A C$ & AF & $\mathrm{CF}$ \\
\hline $\begin{array}{l}\text { Linha de base de } \\
\text { leitura }\end{array}$ & 3 & 3 & & & & & 3 & 18 & 6 & 6 & & 3 & & \\
\hline $\begin{array}{c}\text { Critério para mudança de } \\
\text { fase }(\mathrm{em} \%)\end{array}$ & & & & & & & & 95,2 & & & & 100 & & \\
\hline $\begin{array}{c}\text { Exclusão de números e } \\
\text { numerais }\end{array}$ & & & 2 & 2 & 2 & 2 & & 15 & 6 & 9 & 1 & 2 & 2 & 1 \\
\hline $\begin{array}{c}\text { Critério para mudança } \\
\text { de fase (em \%) }\end{array}$ & & & & & & & & 93,3 & & & & 100 & & \\
\hline Exclusão de palavras & 3 & $9 a$ & & & & & 3 & 18 & 6 & 6 & & $6^{b}$ & & \\
\hline $\begin{array}{l}\text { Critério para mudança } \\
\text { de fase }(\mathrm{em} \%)\end{array}$ & & 100 & & & & & 95,2 & 95,2 & 91,6 & 91,6 & & 100 & & \\
\hline
\end{tabular}

a 3 palavras de ensino, 3 palavras da Linha de Base anterior e 3 palavras de generalização.

b 3 palavras de ensino, 3 palavras de generalização.

\begin{tabular}{|c|c|c|c|c|}
\hline & \multirow{2}{*}{$\begin{array}{l}\text { Pré-Equivalência } \\
\qquad A B\end{array}$} & \multicolumn{2}{|c|}{ Equivalência } & \multirow{2}{*}{$\begin{array}{c}\text { Agrupa-mento } \\
\text { CD }\end{array}$} \\
\hline & & $\mathrm{BC}$ & $\mathrm{CB}$ & \\
\hline Equivalência de palavras & 6 & 12 & 12 & \\
\hline
\end{tabular}

Agrupamento: palavras, números e numerais

Critério para mudança de fase

(em \%)

Equivalência de agrupamento

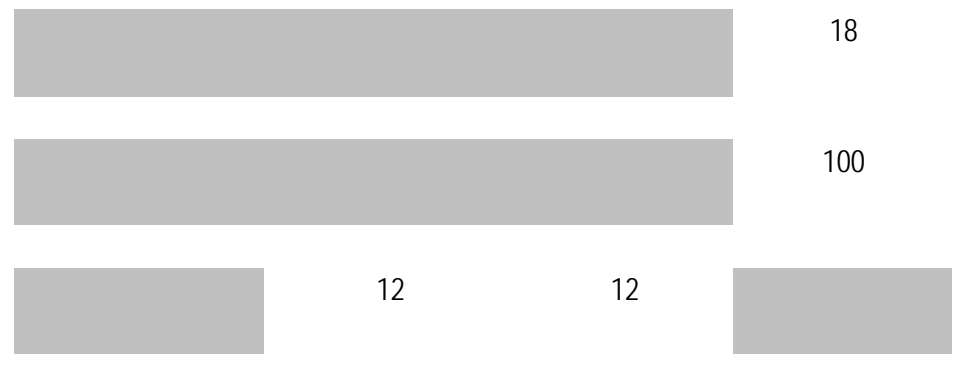

\footnotetext{
c Esse critério foi aplicado apenas para os Ps do pré-primário.
} 


\title{
Ensino de palavra:
}

\author{
p. ex. cama
}

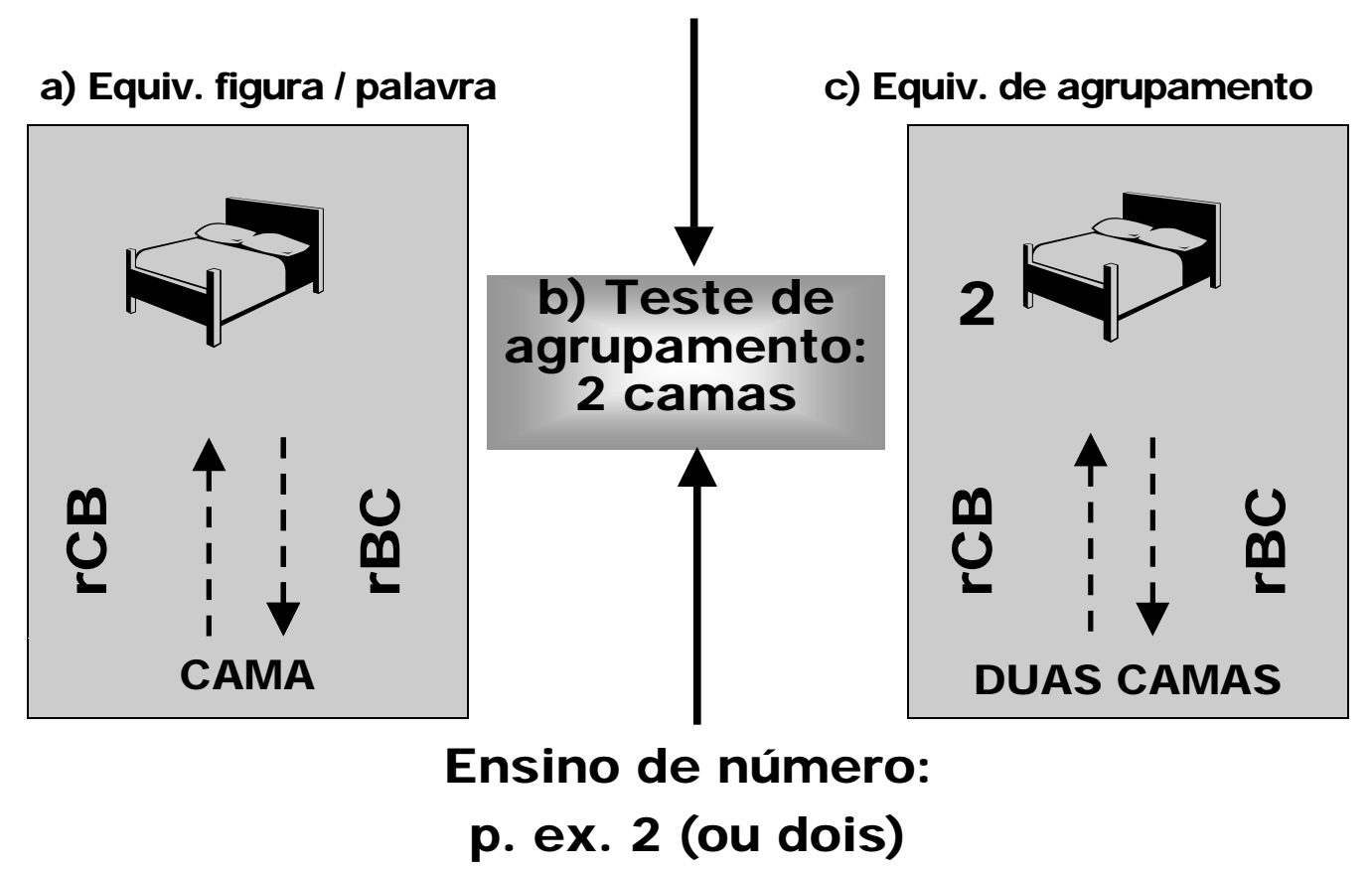

Figura 1. Diagrama do teste de equivalência figura/palavra e palavra/figura (rBC/CB) à esquerda e equivalência de agrupamento à direita.

\section{Teste de equivalência de palavras e figuras ( $\mathrm{rBC} / \mathrm{CB}$ )}

Antes de iniciar a etapa de equivalência, a identificação correta das figuras foi novamente conseqüenciada. Em seguida, era aplicado o teste de equivalência das relações BC, apresentando a figura como estímulo-modelo e os nomes impressos das figuras como estímulos de comparação, sendo um deles o correto, ou seja, aquele que corresponde ao estímulo-modelo. A escolha correta do nome da figura correspondente à figura não recebia qualquer conseqüência, o mesmo ocorrendo com a escolha incorreta. Na seqüência, o nome de uma das figuras (palavra impressa) funcionou como modelo e as figuras como estímulos de comparação, sendo um deles, o correto. Novamente, a escolha correta da figura correspondente ao nome da figura não recebia qualquer conseqüência, o mesmo ocorrendo com a escolha incorreta.

\section{Teste de agrupamento de palavras, de números e numerais ( $r C D)$}

Nesta etapa os números e as palavras de ensino ${ }^{7}$ nas exclusões foram testados conjuntamente, cujos exemplos podem ser vistos no Agrupamento 1 (CD): números/numerais e palavras como aparece na Tabela 2.

\section{Teste de equivalência de agrupamento de palavras, números e numerais ( $\mathrm{rBC} / \mathrm{CB}$ )}

Esse teste foi semelhante ao descrito para testar as equivalências entre palavras e figuras e entre numerais e números, exceto que as unidades testadas foram compostas pelo agrupamento de números/palavras e de numerais/palavras, como pode ser visto na Tabela 2; além dessa diferença, no teste de equivalência de agrupamento de palavras, números e numerais não foi realizado Pré-teste.

\section{RESULTADOS}

Os resultados são apresentados na forma de porcentagem e foram calculados por meio da divisão do número de acertos pelo total do número de tentativas de cada etapa. Nas figuras que se seguem, estão descritas as relações AC de palavras e de números referentes aos acertos apresentados pelos Ps nas etapas de Pré e Pós-Testes, as relações CD das sessões de Agrupamento (AG) e as relações $B C / C B$ das sessões de 
equivalência de agrupamento de números e palavras de ensino ${ }^{8}$.

O primeiro conjunto de dados aparece na Figura 2 e referem-se às porcentagens de acertos do teste inicial (antes do início do procedimento de ensino) e do teste final (depois de encerrado o procedimento). No gráfico superior esquerdo, relativo à identificação de números, pode-se ver que sete Ps $(4,6,9,10,11,12$ e 13) no teste inicial apresentam 100 por cento de acertos, cinco deles (1, 2, 5, 7 e 8) apresentam porcentagens variando entre 30 e 60 e um P (P3) apresenta zero por cento de acerto. Já, no teste final, todos os Ps apresentam 100 por cento de acertos. No gráfico superior direito, relativo à identificação de numerais, pode-se ver que apenas um $\mathrm{P}$ (P5), no teste inicial, apresenta acertos, cuja porcentagem é de 73 por cento. Já, no teste final, oito Ps (1, 2, 5, 9, 10, 11, 12 e 13) acertam todas as tentativas. Três deles ( 3 , 4 e 6 ) com porcentagens entre 35 e 65 por cento e dois deles (7 e 8) apre- sentam 82 por cento de acertos. No gráfico inferior esquerdo, relativo à identificação de quantidades, pode-se ver que seis Ps $(1,4,6,9,10$ e 12$)$, no teste inicial, apresentaram acertos, com porcentagem de 100 por cento; cinco Ps (3, 5, 7, 8 e 13) apresentam acertos cuja porcentagem varia entre 65 e 90 e dois Ps (2 e 11) com valores de 44 e 56 por cento respectivamente. Já, no teste final, a porcentagem é de 100 por cento para todos os Ps. No gráfico inferior direito, relativo à leitura de palavras, pode-se ver que apenas um P (P5), no teste inicial, apresenta acertos, com porcentagem de 62 por cento. No teste final, podem-se observar três agrupamentos distintos de acertos: para os Ps 3, 4, 6 e 7, a porcentagem de acertos varia entre 0 e 45 por cento; para os Ps 8 e 11, a porcentagem é de 76 e 81 por cento e, para os demais Ps $(1,2,5,9$, 10,12 e 13), a porcentagem de acertos varia entre 98 e 100 por cento.

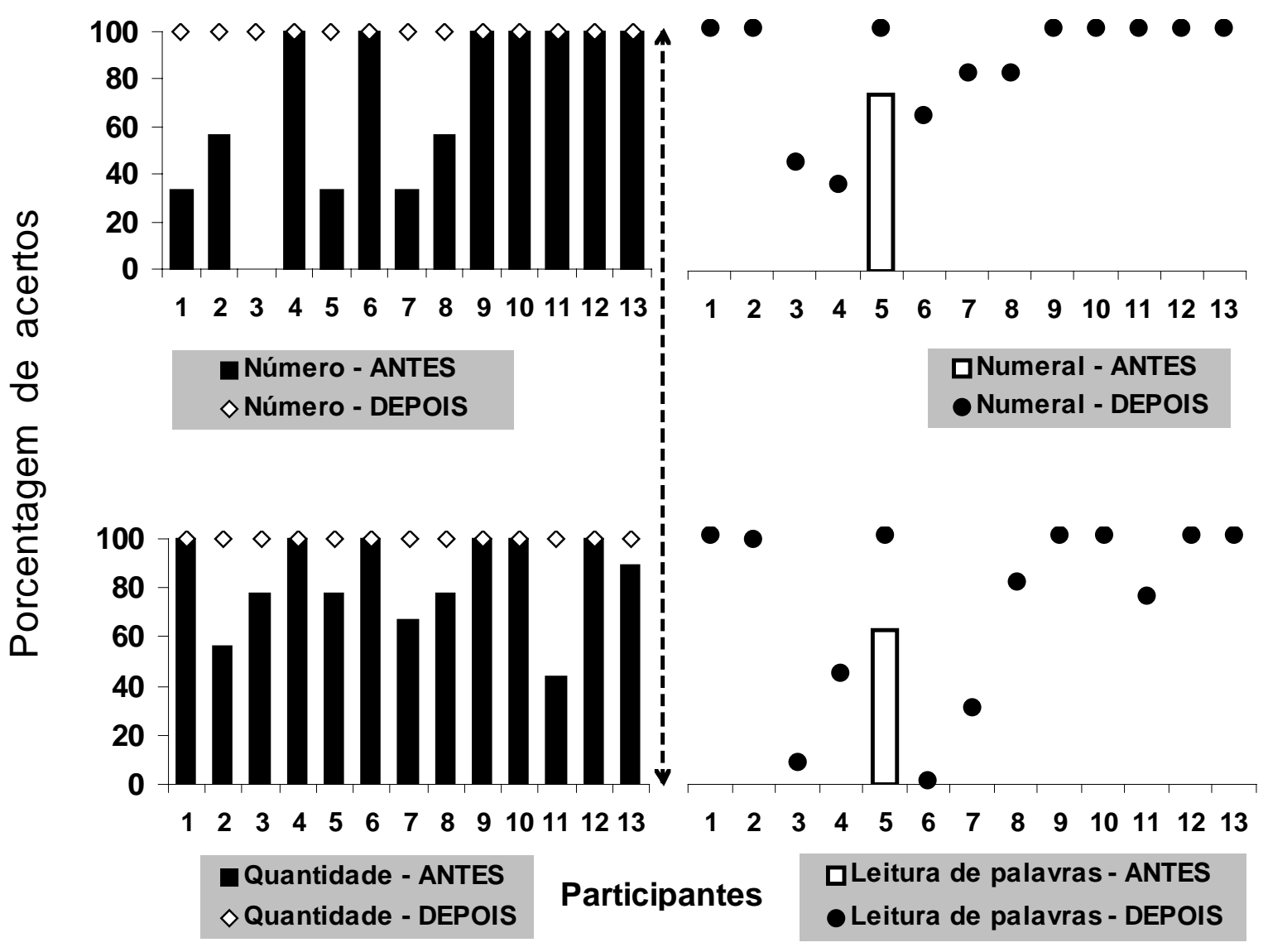

Figura 2. Porcentagem de acertos nos testes iniciais e finais de leitura de números e numerais (parte superior) e de quantidades e leitura de palavras (parte inferior). 
As Figuras 3, 4, 5 e 6 apresentam a porcentagem de acertos nos Pré e Pós-Testes das Exclusões de identificação de números e de numerais, de leitura de palavras e Testes de Agrupamento.

Pode-se verificar na Figura 3, relativa aos Ps 1, 2, 3 e 4, que as porcentagens de acertos de identificação de números nos Pós-T é sempre superior à porcentagem verificada nos Pré-T, com exceção da sessão 2 de P1 e sessão 3 de P3. Em relação à leitura de palavras, a variabilidade é mais acentuada do que a variabilidade observada na identificação de números. Dos quatro Ps analisados, dois deles (P2 e P4) terminaram a etapa com acertos de 100 por cento nas duas últimas sessões; os outros dois (P1 e P3) apresentaram, na última sessão, desempenho melhor no Pré-T do que no PósT. Em relação aos dados de agrupamento, pode-se observar que os Ps 1 e 2 leram com acertos poucas (entre 0 e 11 por cento para P1 e 0 e 17 para P2) unidades compostas por números e palavras. Por sua vez, o desempenho dos Ps 3 e 4 (entre 67 e 100 por cento) é percentualmente superior ao desempenho dos Ps 1 e 2 .

Na Figura 4, relativa aos Ps 5, 6 e 7, pode-se verificar que as porcentagens de acertos de identificação de números nos Pós-T é superior à porcentagem apresentada no Pré-T para todos os Ps. Em relação à leitura de palavras, há uma variabilidade mais acentuada para P5 do que para os Ps 6 e 7. As duas últimas sessões, com porcentagem de acertos próxima de 100 por cento no Pré-T para os três Ps, indicam que os Ps já liam as palavras apresentadas mesmo antes da etapa de ensino, cujo controle manifesta-se novamente na etapa do Pós-T com 100 de acerto para P6 e P7 e 90 por cento para P5. Em relação aos dados de agrupamento, pode-se observar que esses três Ps leram com alta porcentagem de acertos (entre 90 e 100 por cento) todas as unidades apresentadas, com exceção das unidades apresentadas nas sessões 1 e 2 de P5.

Na Figura 5, relativa aos Ps 8, 9 e 10, pode-se verificar que as porcentagens de acertos de identificação de números nos Pós-T é superior à porcentagem apresentada no Pré-T para todos os Ps, com exceção de três sessões (1, 3 e 4) para P10. Em relação à leitura de palavras, há uma variabilidade mais acentuada para P8 do que para os Ps 9 e 10. As porcentagens das três últimas sessões, com acertos próximos de 100 por cento no Pré e Pós-T para os três Ps, indicam que eles já liam as palavras apresentadas mesmo antes da etapa de ensino, cujo controle manifesta-se novamente na etapa do Pós-T com 100 de acerto para os três Ps. Em relação aos dados de agrupamento, pode-se observar que os três Ps leram com alta porcentagem de acertos (entre 89 e 100 por cento para os três Ps, com exceção da $1^{\text {a }}$ sessão de agrupamento de P9, cujo valor é da ordem de 77 por cento) todas as unidades apresentadas.

Na Figura 6, relativa aos Ps 11, 12 e 13, pode-se verificar que as porcentagens de acertos de identificação de números nos Pós-T é superior à porcentagem apresentada no Pré-T para todos os Ps. Em relação à leitura de palavras, há uma variabilidade mais acentuada para P11 do que para os Ps 12 e 13 . As porcentagens das três últimas sessões, com acertos próximos de 100 por cento no Pré e Pós-T para os três Ps, indicam que eles já liam as palavras apresentadas mesmo antes da etapa de ensino, cujo controle manifesta-se novamente na etapa do Pós-T com alta porcentagem de acertos para os três Ps. Em relação aos dados de agrupamento, pode-se observar que os três Ps leram com alta porcentagem de acertos (entre 83 e 100 por cento) todas as unidades apresentadas, com exceção das unidades apresentadas nas sessões 3 de P12 (55 por cento) e sessões 3 e 4 de P13 (77 e 67 por cento respectivamente).

A Figura 7 foi elaborada com os acertos relativos aos números, numerais e palavras dos testes de agrupamento, organizada com as porcentagens em separado de números/palavras e numerais/palavras (respectivamente gráficos da esquerda superior e inferior). Nos gráficos da direita encontram-se as porcentagens dos agrupamentos de números e palavras (superior) e numerais e palavras (inferior). Nos gráficos da esquerda estão alocados os acertos dos agrupamentos em que apenas um dos elementos do agrupamento foi lido corretamente (números e ou palavras - superior; numerais e ou palavras - inferior). Nos gráficos da direita estão alocados os acertos dos agrupamentos em que ambos os elementos foram lidos corretamente. Em relação a números (ao lado de palavras - superior esquerdo), estes foram identificados pelos Ps 1, 2, 3, $4,5,12$ e 13 com porcentagens entre 0 e 50 por cento com valores mais altos para os Ps 1 e 2 (28 e 50 respectivamente). Em relação a palavras (ao lado de números - superior esquerdo), a porcentagem de acertos é praticamente zero para todos os Ps. Em relação a numerais (ao lado de palavras - inferior esquerdo), a porcentagem de acertos varia entre 0 e 20 por cento para os Ps 1, 2, 3, 4, 5, 9, 11, 12 e 13. Em relação aos demais a porcentagem é de zero por cento. Em relação a palavras (ao lado de numerais - inferior esquerdo), a porcentagem varia entre 0 e 20 por cento de acertos para os Ps 2, 3, 4, 5, 6, 9 e 12. Para os demais a porcentagem de acertos é de zero por cento. Em resumo, 
há mais acertos para números do que para numerais quando estes estão ao lado de palavras. Em relação às palavras, em ambas as situações a porcentagem de acertos é praticamente idêntica, ou seja, zero ou próxima de zero.

Os gráficos da direita (superior e inferior) apresentam a porcentagem da leitura do agrupamento em que ambas as unidades foram lidas corretamente. Verifica-se que o nível de acertos é superior quando a palavra vem acompanhada de números do que quando vem acompanhada de numerais. No primeiro caso (superior), há apenas dois Ps (1 e 2) que não leram (com porcentagens de zero e 11 por cento respectivamente). Para os demais Ps os níveis variam entre 85 e 100 por cento. No segundo caso (inferior), três Ps (1, 2 e 5) apresentam porcentagem baixa de acertos, com níveis mais baixos para os Ps 1 e 2 . Para os demais, o nível de acerto varia entre 82 e 100 por cento.

A Figura 8 apresenta os resultados dos Testes de Equivalência das relações BC/CB das palavras e figuras de ensino. Observa-se que todos os Ps, exceto um (P2), responderam com alta porcentagem de acertos (entre 87 e 100 por cento) às relações palavras/figuras e figuras/palavras.

A Figura 9 apresenta os resultados do Teste de Equivalência de Agrupamento das relações BC/CB das unidades completas (palavras e números ensinados). Pode ser visto no gráfico superior esquerdo (Eq leit) que as porcentagens de acerto da maioria dos Ps estão localizadas acima de 90 por cento, exceto para os Ps 2 e 8 , cujos valores da $1^{\text {a }}$ sessão de equivalência localizam-se entre 80 e 90 por cento e P13, cujo valor percentual é de aproximadamente 90 por cento na $2^{\text {a }}$ Equivalência. Na equivalência de números (gráfico superior direito), os resultados mostram-se inferiores em comparação à equivalência de leitura de palavras (superior esquerdo) com cinco Ps $(1,2,5,12$ e 13) com porcentagens abaixo de 90 por cento, contudo o resultado da $3^{\text {a }}$ sessão de equivalência é de 100 por cento para todos, exceto para os Ps 1 e 2 que realizaram apenas a $1^{\text {a }}$ sessão de equivalência. Na equivalência de agrupamento (Eq AG - gráfico inferior), a maioria dos valores situa-se acima de 90 por cento. A exceção fica por conta de três deles (Ps 1, 2 e 5) cujos valores percentuais encontram-se abaixo de 90 por cento. Para os Ps 1 e 2 os valores são zero e para o P5 a porcentagem da última sessão não vai além de 80 por cento. O P11, embora com um dos valores abaixo de 90 por cento ( $2^{\mathrm{a}}$ sessão), responde dentro da faixa de 90 por cento na última sessão. Pode ser visto que as porcentagens de acerto da maioria dos Ps estão localizadas acima de 90 por cento. A exceção fica por conta de três deles (Ps 1, 2 e 5) cujos valores percentuais encontram-se abaixo de 90 por cento. Para os Ps 1 e 2 os valores são zero e para o P5 a porcentagem da última sessão não vai além de 80 por cento. O P11, embora com um dos valores abaixo de 90 por cento $\left(2^{\mathrm{a}}\right.$ sessão), responde dentro da faixa de 90 por cento na última sessão.

A Figura 10 apresenta o número da exclusão alcançada no ensino das classes de respostas (parte superior) e o número médio de sessões em cada uma das exclusões realizadas (parte inferior). Pode-se ver que os Ps 1 , 3 e 5 alcançaram apenas $2 / 3$ do total dessas exclusões, com exceção de P1 que realizou apenas uma exclusão. Os demais Ps realizaram todas as exclusões programadas. Na parte inferior da figura, encontra-se o número médio de sessões em cada uma das exclusões do programa de ensino. Nota-se que, na medida em que o procedimento se desenvolve, o número médio de sessões necessárias para alcançar o critério de desempenho para mudar de exclusão diminui gradualmente, indicando um processo de aprender a aprender (learning set).

Os Ps aprenderam não apenas as palavras e números de ensino como também demonstraram repertório emergente de leitura de outras palavras. Como pode ser visto na Figura 11, no teste final de leitura de palavras, dos 13 Ps, 10 leram corretamente as palavras de ensino, exceto P5 que leu apenas 65 por cento, com exceção de P1 e P2 que leram 5 e 20 por cento respectivamente. Em relação às outras palavras, dos 13 Ps, 7 leram em torno de 100 por cento, 2 (P6 e P9) leram em torno de 60 por cento e quatro não leram (P1, P2, P3 e P5). 

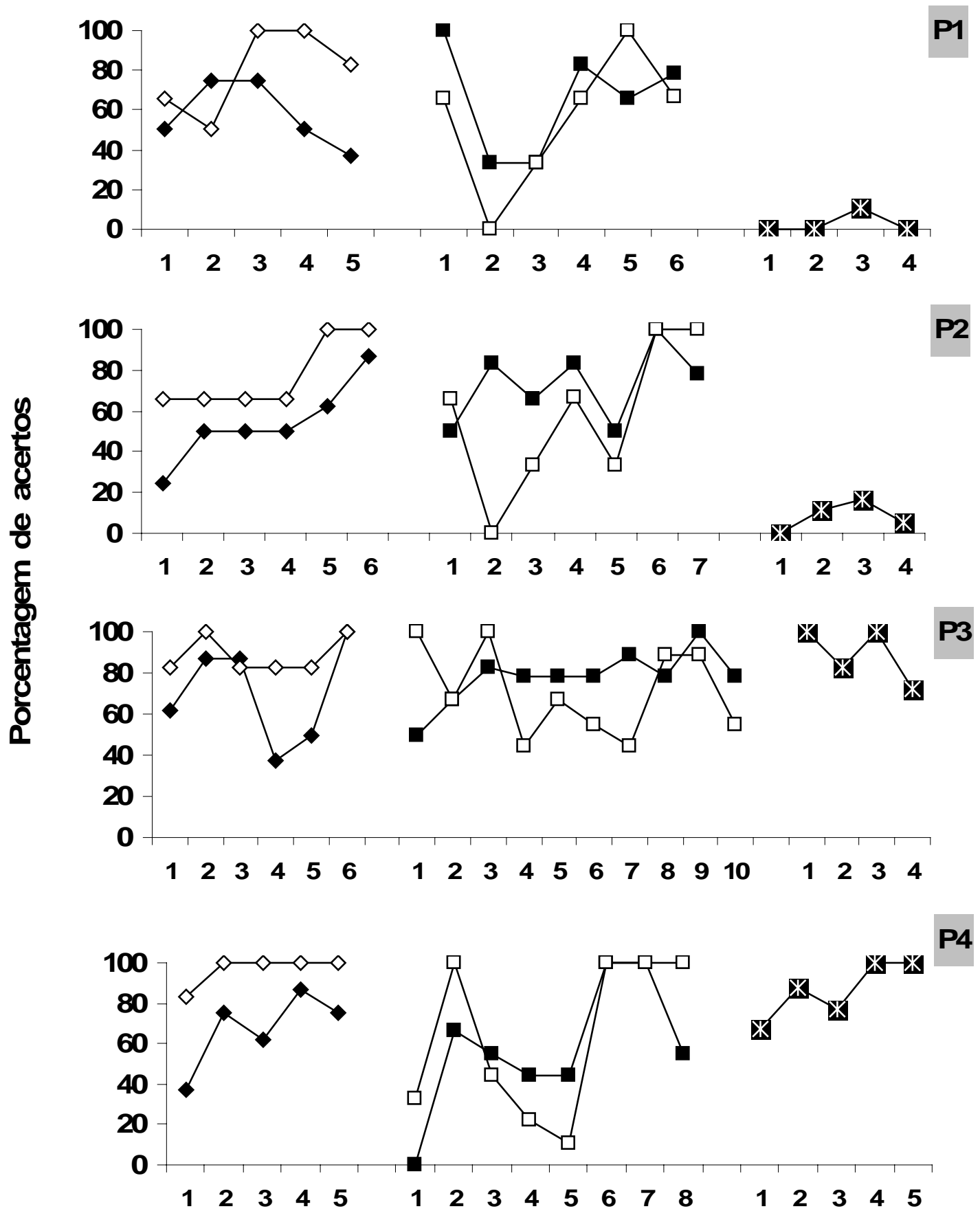

Sessões

\section{$\multimap$ Pre-Tnu $\prec$ Pos-Tnu $\rightarrow$-Pre-Tlei $\rightarrow-$ Pos-Tlei $\rightarrow$ - AG}

Figura 3. Porcentagem de acertos nos pré e pós testes de leitura de números, leitura de palavras e testes de agrupamento (números / numerais + palavras) dos participantes 1, 2, 3 e 4. 

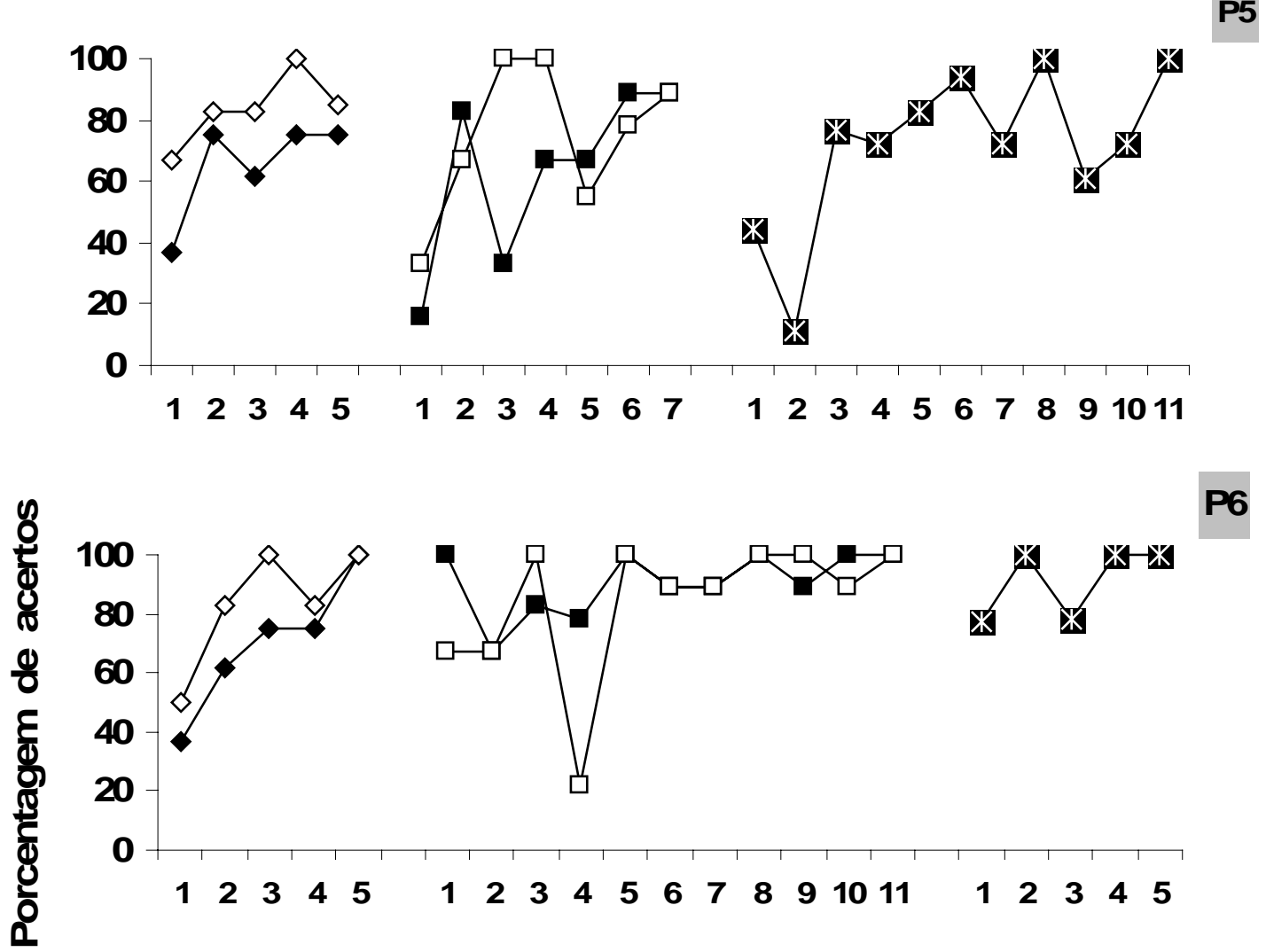

P7

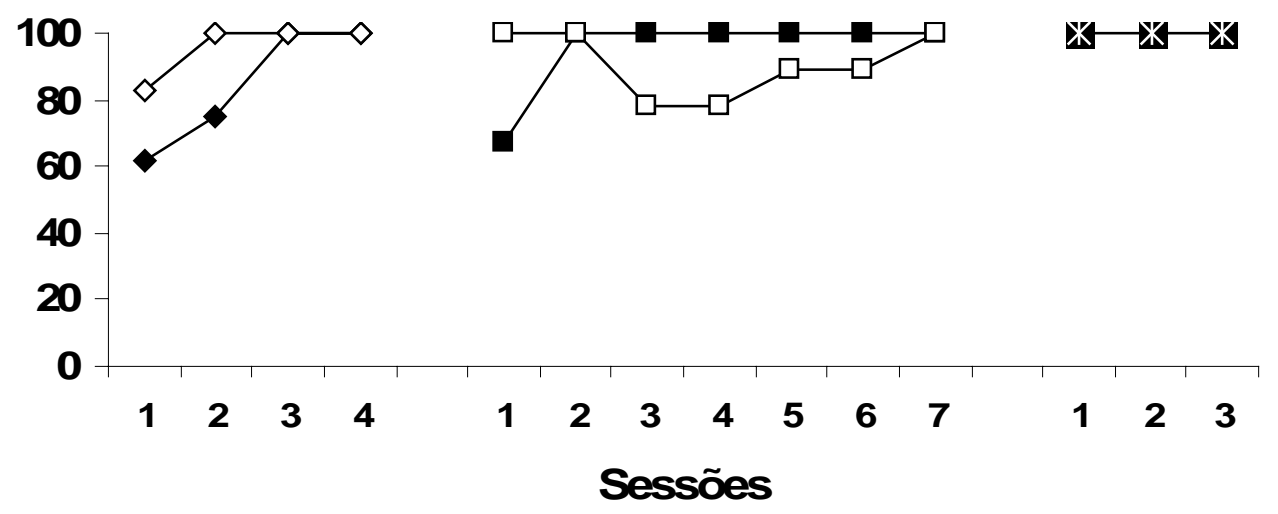

\section{$\multimap$ Pre-Tnu $\leadsto$ Pos-Tnu $\rightarrow-$ Pre-Tlei $\rightarrow-$ Pos-Tlei $\rightarrow \mathbb{X}$-AG}

Figura 4. Porcentagem de acertos nos pré e pós testes de leitura de números, leitura de palavras e testes de agrupamento (números / numerais + palavras) dos participantes 5, 6, e 7. 


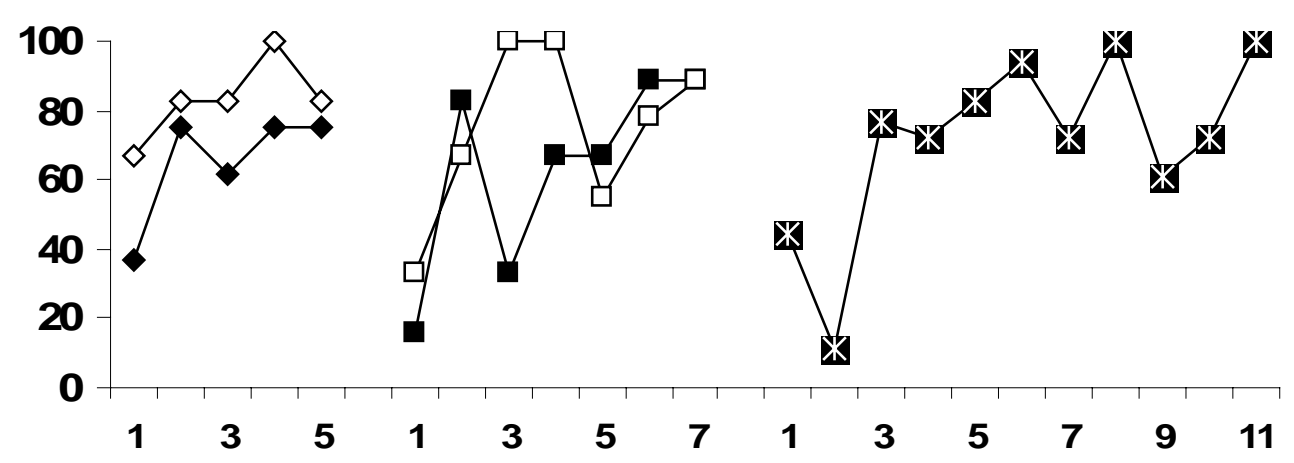

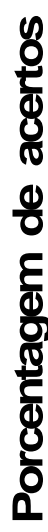

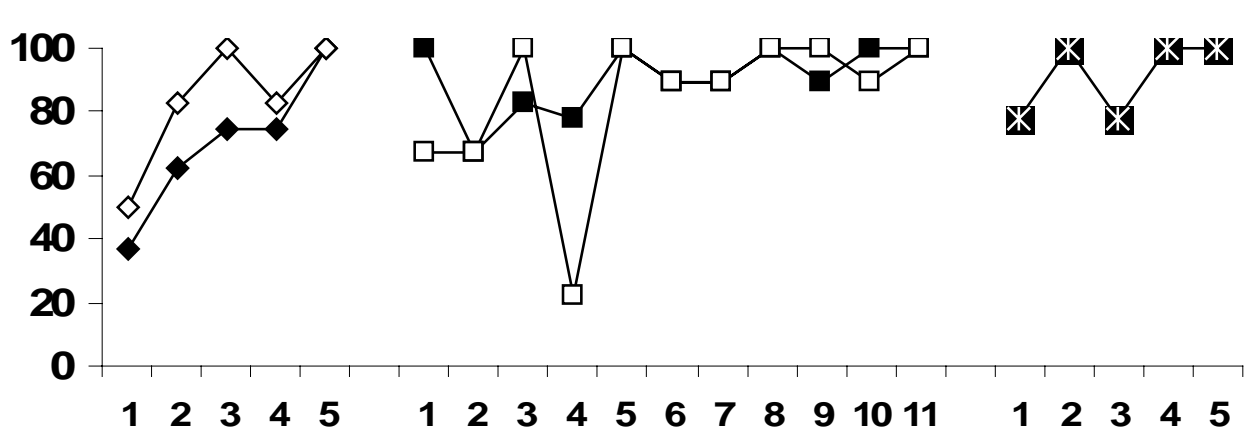

P6

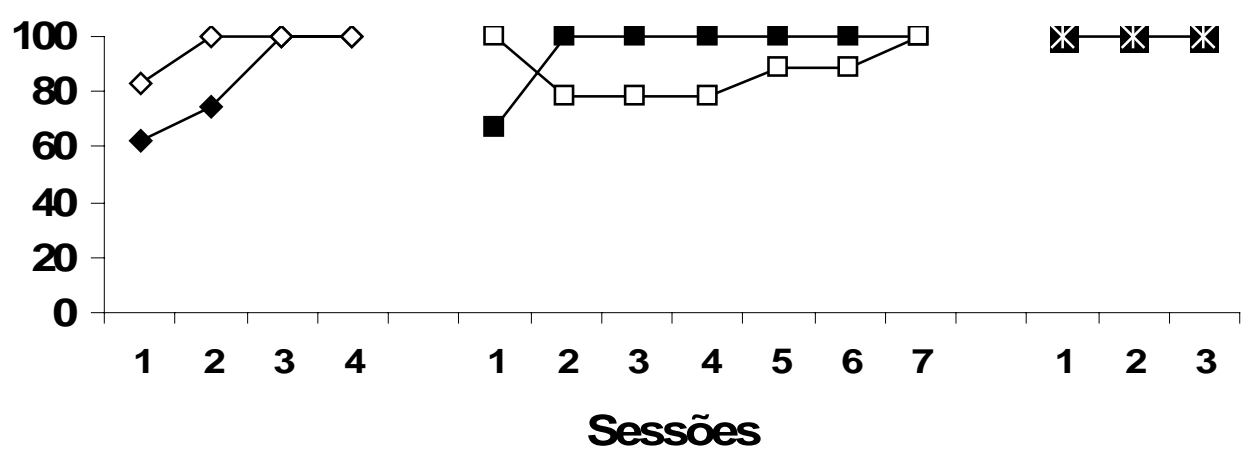

\section{$\neg$ Pre-Tnu $\prec$ Pos-Tnu $\rightarrow$ Pre-Tlei $-\square-$ Pos-Tlei $\rightarrow \mathbb{X}-$ AG}

Figura 5. Porcentagem de acertos nos pré e pós testes de leitura de números, leitura de palavras e testes de agrupamento (números / numerais + palavras) dos participantes 8, 9, e 10. 
P11

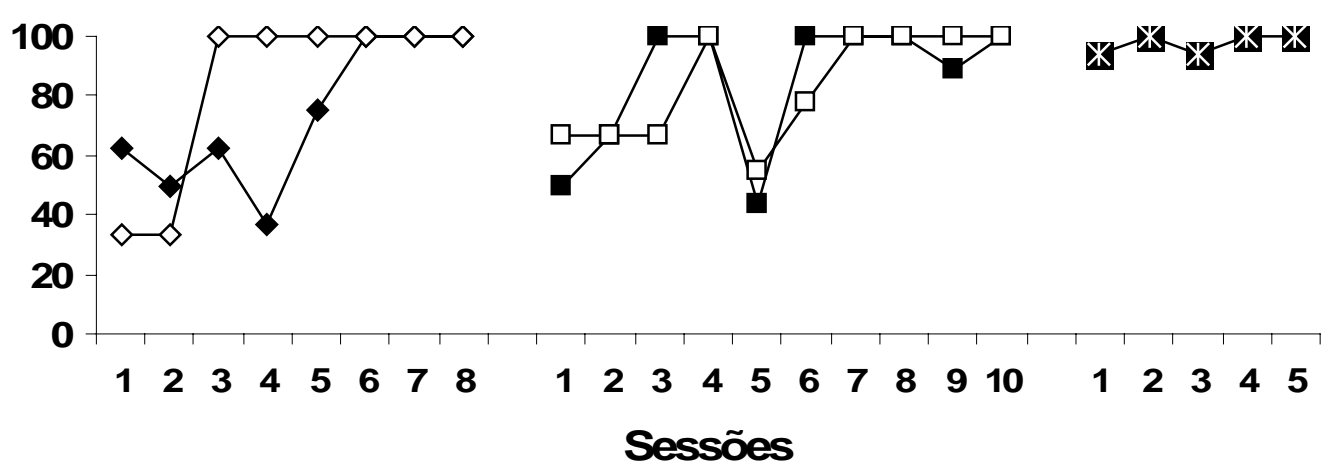

P12

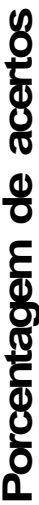

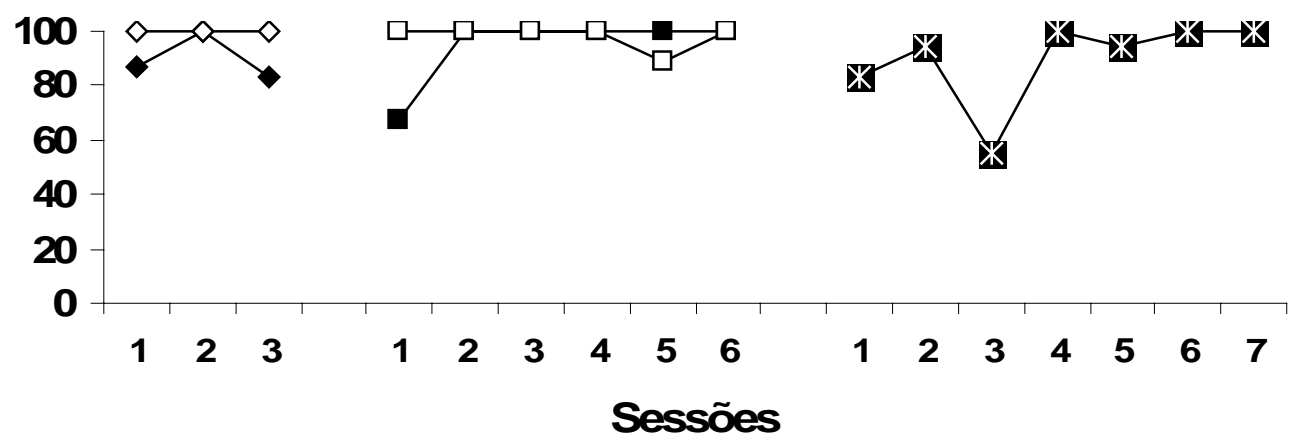

P13

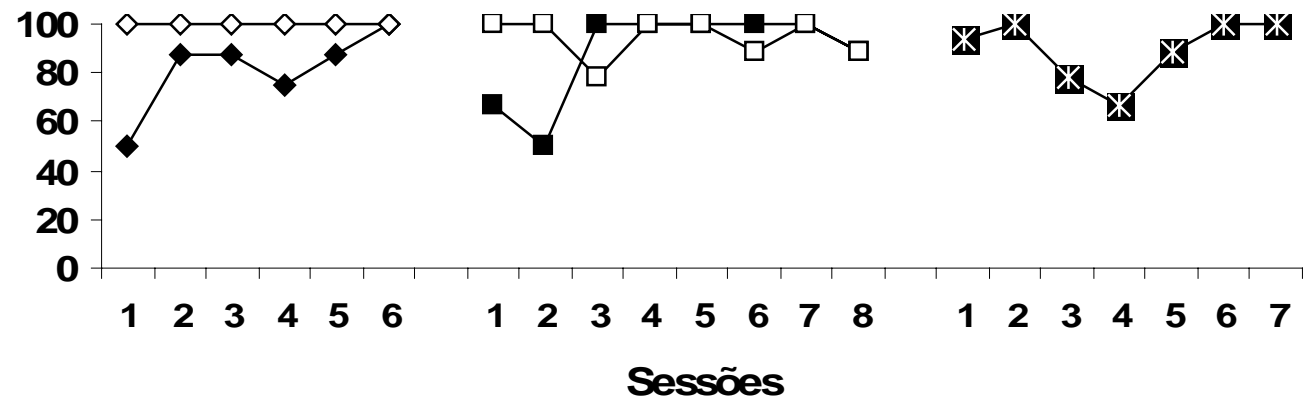

$\neg$ Pre-Tnu $\prec$ Pos-Tnu $\rightarrow-$ Pre-Tlei $\rightarrow-$ Pos-Tlei $\rightarrow \mathbb{x}-$ AG

Figura 6. Porcentagem de acertos nos pré e pós testes de leitura de números, leitura de palavras e testes de agrupamento (números / numerais + palavras) dos participantes 11, 12, e 13. 


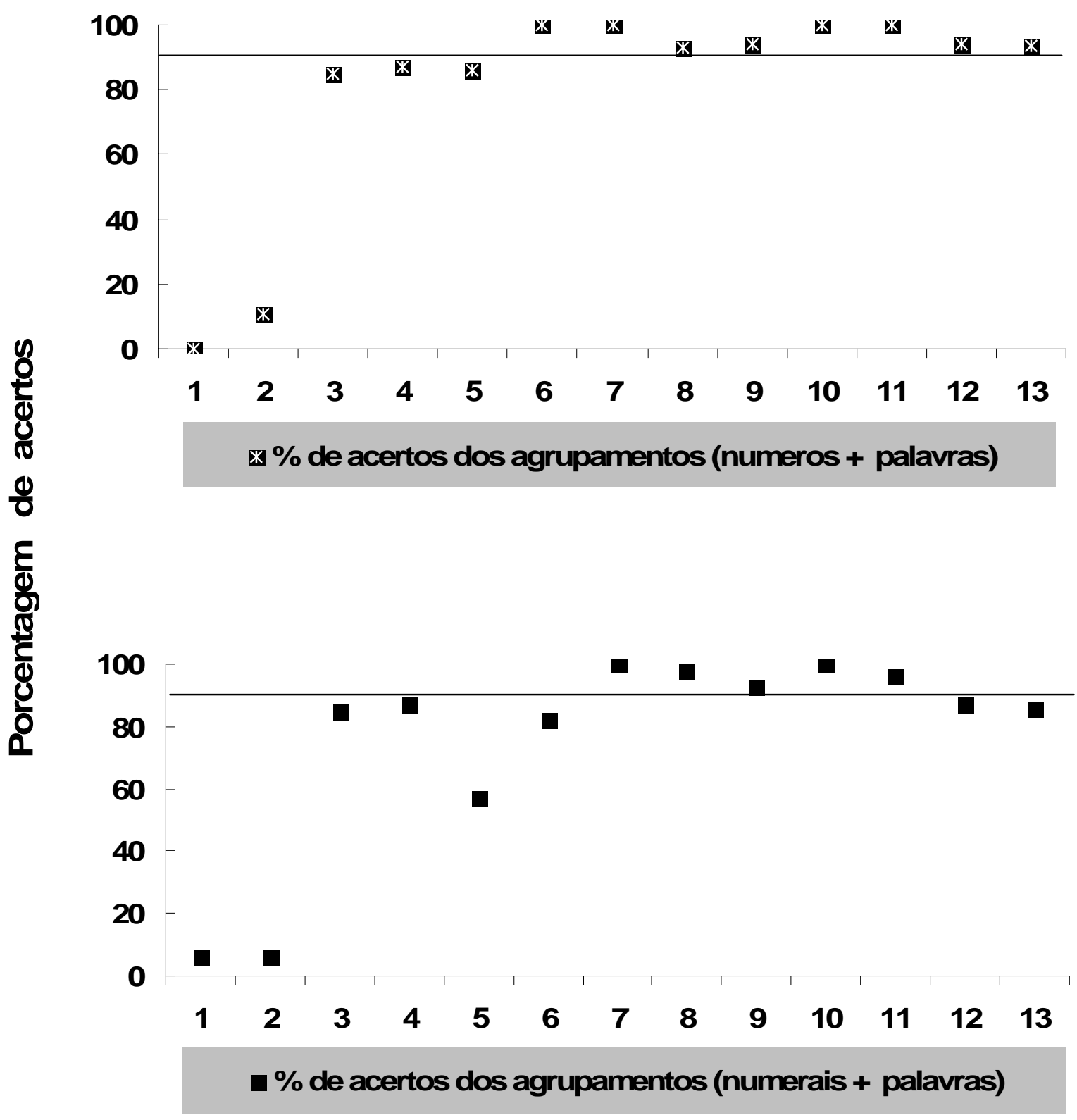

\section{Participantes}

Figura 7. Porcentagem de acertos no teste de agrupamento de leitura de números agrupados com palavras (parte superior) e porcentagem de acertos no teste de agrupamento de leitura de numerais agrupados com palavras (parte inferior). 


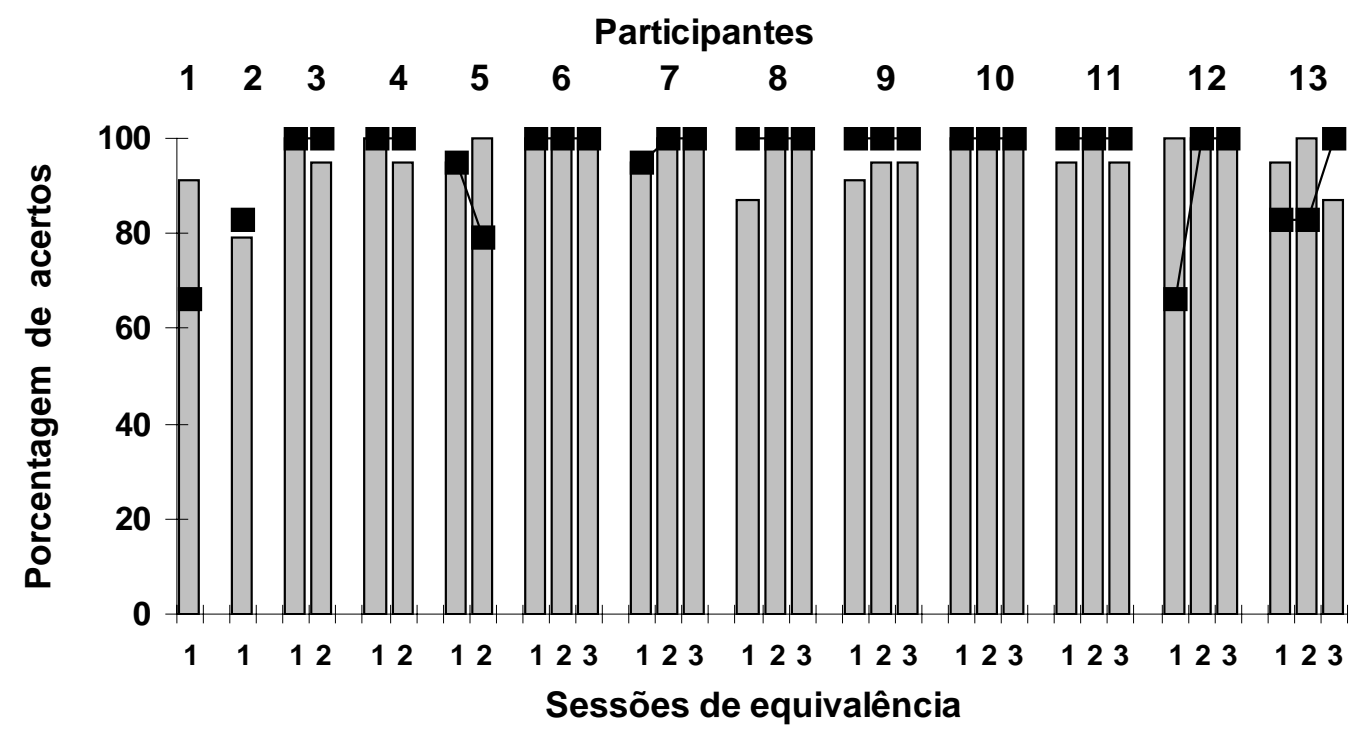

Relação BC/CB de palavras

- Relação $\mathrm{BC} / \mathrm{CB}$ de números

Figura 8. Porcentagens de acertos nos Testes de Equivalência (Relações BC/CB).

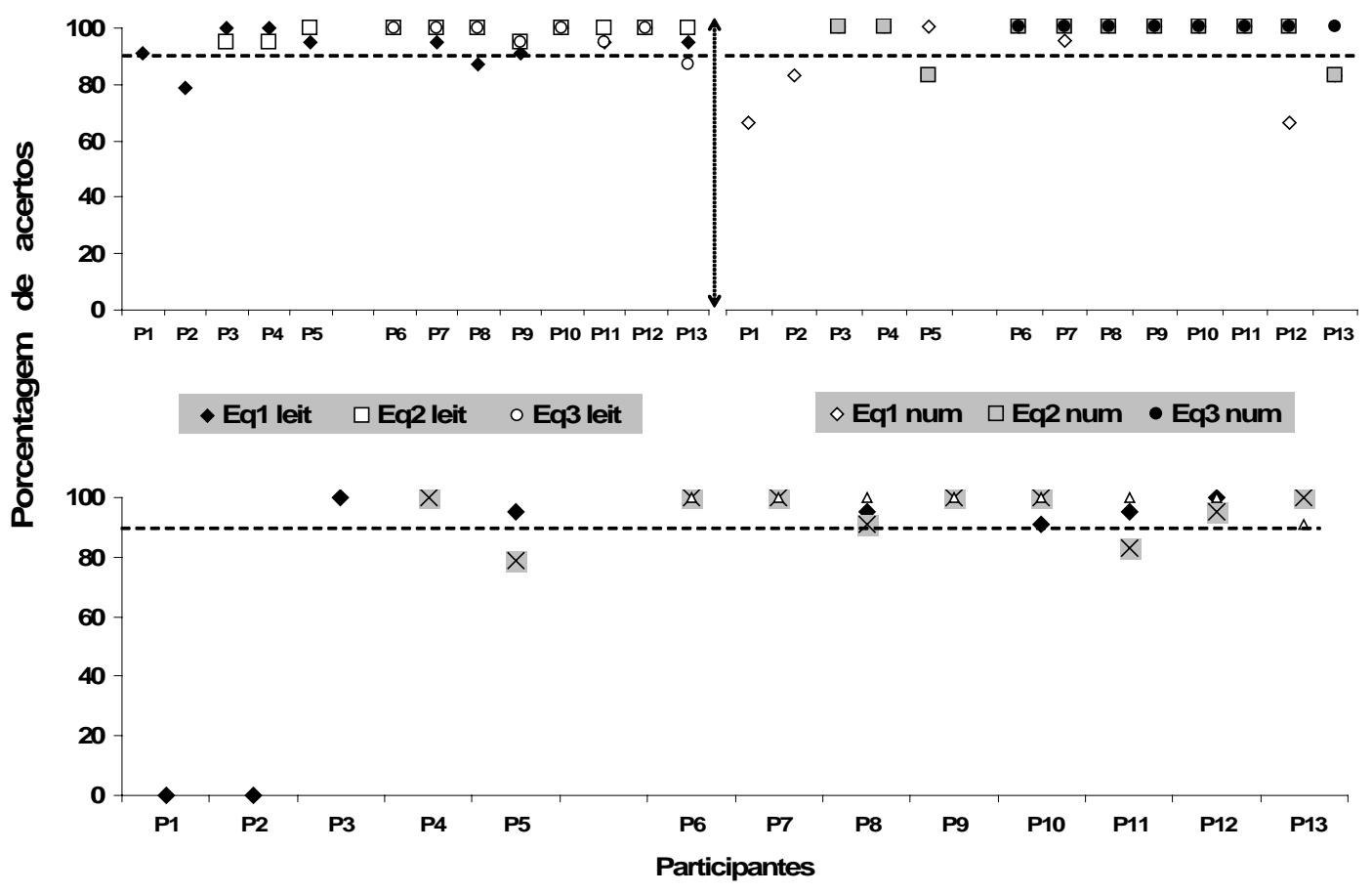

$\bullet$ Eq AG1 $\times$ EqAG2 $\triangle$ EqAG3

Figura 9. Porcentagens de acertos no teste de equivalência de agrupamento: leitura de palavras (gráfico superior esquerdo); leitura de números (gráfico superior direito); leitura das unidades completas (números + palavras) (gráfico inferior). A linha pontilhada horizontal, localizada no valor 90 da escala, agrupa as porcentagens entre 90 e 100 por cento. 


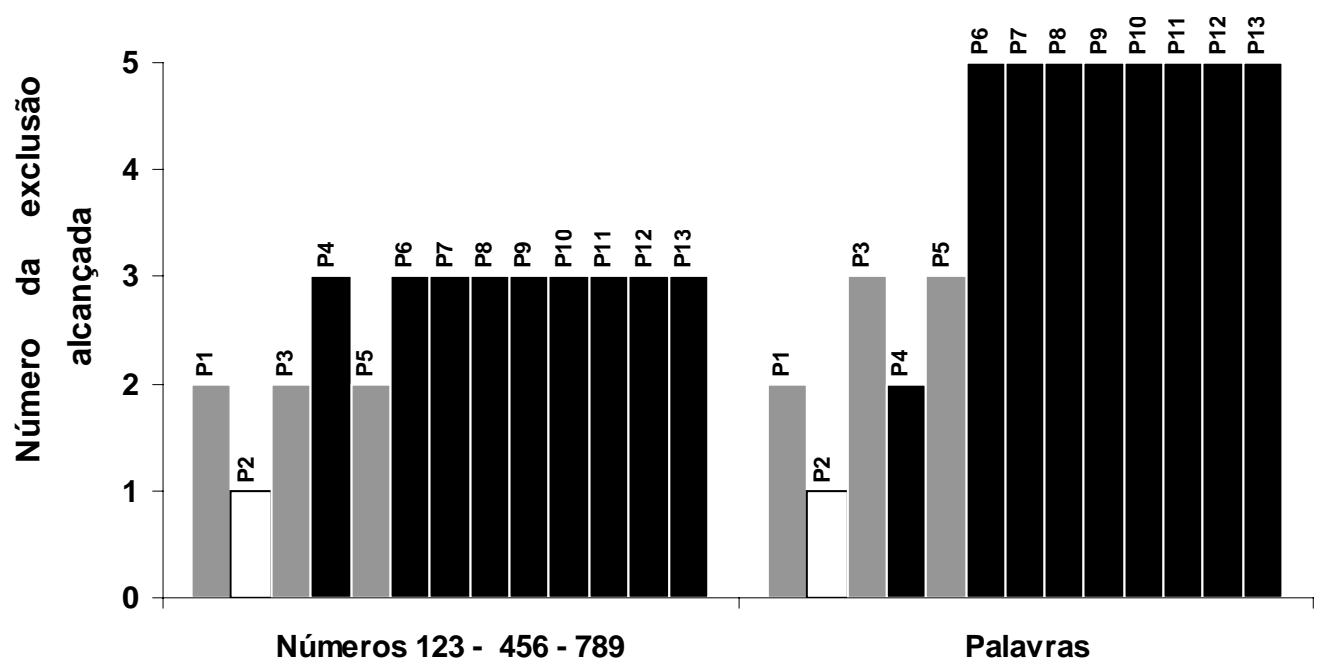

\section{Classes de respostas ensinadas}

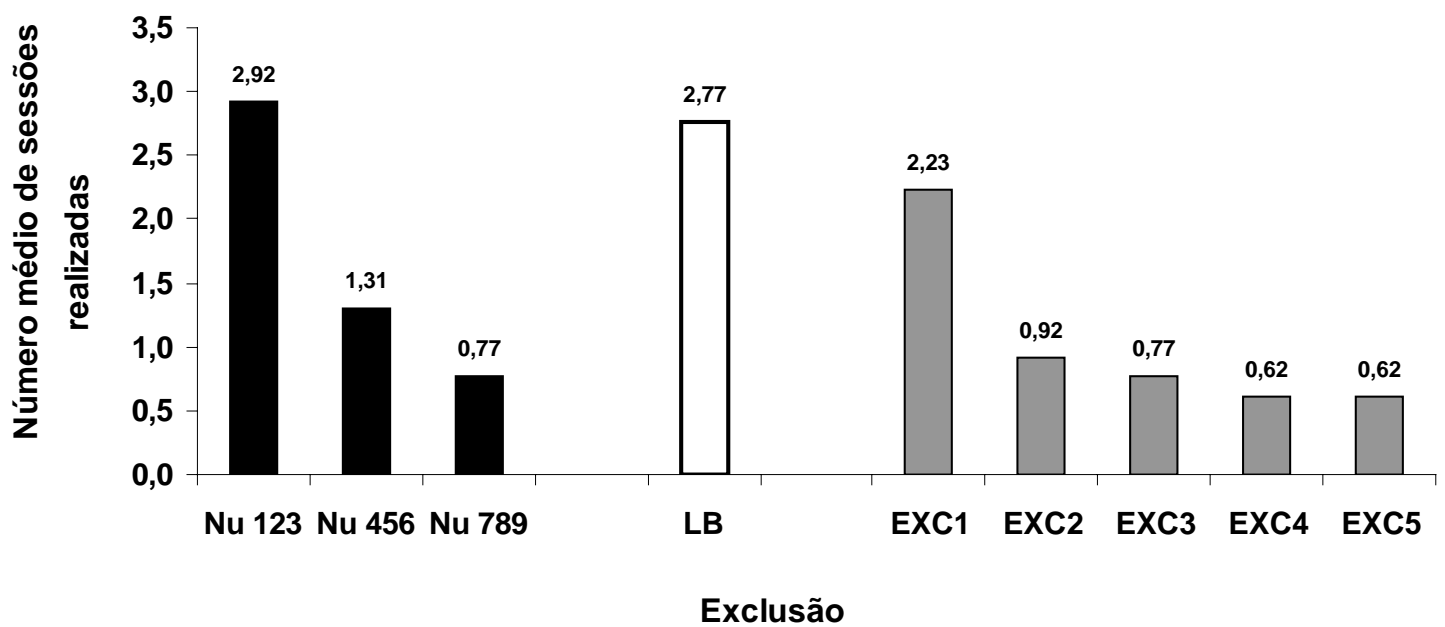

Figura 10. Número da exclusão alcançada no ensino das classes de respostas (parte superior) e número médio de sessões realizadas em cada uma das exclusões realizadas (parte inferior). 


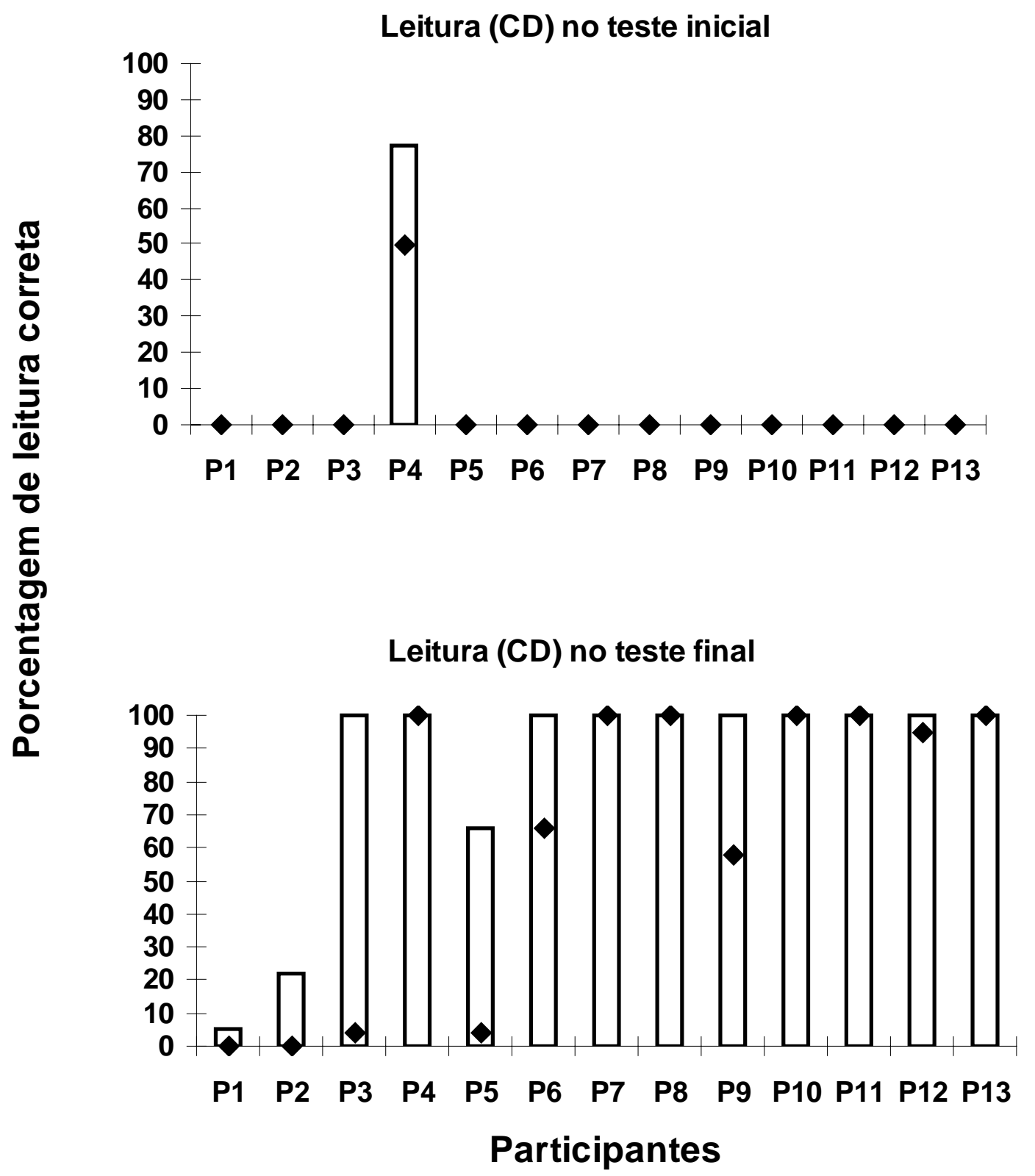

\section{口Palavras de ensino $\quad$ Outras palavras}

Figura 11. Porcentagem de leitura correta nos testes inicial (parte superior) e final (parte inferior) das palavras ensinadas (18) e de outras palavras (24) também apresentadas nesses testes, porém não ensinadas. 


\section{DISCUSSÃO}

Os resultados do presente estudo mostram que a pergunta de pesquisa foi respondida, pois os comportamentos de ler e escrever palavras, ensinados independentemente do comportamento de ler números, foram emitidos juntos na situação de teste. Dos 13 Ps apenas dois (P1 e P2) não leram as unidades de agrupamento compostas por números, numerais e palavras. Os Ps leram não apenas as unidades compostas por números, numerais e palavras de ensino nas sessões de exclusão, mas leram também novos numerais (ensinou-se "um” e "dois” e leram "uma” e "duas") e palavras no plural (cama/camas; mago/magos; calo/ calos [a relação completa encontra-se na Tabela 1]).

Como explicar a alta porcentagem de acertos do desempenho emergente nas etapas de agrupamento? Poder-se-ia argumentar que, por se constituírem em sessões repetidas de teste e como estudos da literatura mostram que a repetição de testes resulta na melhoria do nível de acerto (Bush, Sidman e de Rose, 1989; de Rose, Garotti e Ribeiro, 1992), os Ps poderiam ter respondido corretamente em função dessas condições. Contudo, semelhante argumento não se sustentaria, pois dos 13 Ps, nove responderam com alto nível de acertos, já na primeira sessão de agrupamento.

A explicação mais provável pode ser devida ao fato dos estímulos utilizados serem equivalentes, não apenas isoladamente (palavras/figuras [letra "a" Figura 1], mas também quando faziam parte das unidades de agrupamento (letra "c" - Figura 1). No caso da equivalência de agrupamento, os estímulos foram testados a partir dos elementos apresentados anteriormente (como mostram as letras “a” e "b" da Figura 1), sendo que em nenhuma etapa do procedimento ensinou-se o participante a responder frente a unidades de agrupamento. Elas foram apresentadas aos Ps em situação de teste, portanto sem qualquer contingência de reforçamento experimentalmente planejada.

As relações presentes na Figura 2 mostram claramente que o procedimento produziu mudanças comportamentais significativas no repertório dos Ps. Porcentagem de ler números (gráfico superior esquerdo) aumenta significativamente para todos os Ps no Teste Final (Número - DEPOIS), indicando que as contingências presentes nas sessões de ensino desses comportamentos levaram os Ps a responder com porcentagens de acertos superiores àquelas verificadas no Teste Inicial (Número - ANTES). Ler numerais (gráfico superior direito) e ler palavras (gráfico inferior direito), por sua vez, muda de maneira expressiva em termos percentuais no Teste Final. Dos 13 Ps, 10 mostram acertos próximos de 100 por cento ao ler numerais e, na leitura de palavras, dos 13 Ps, 9 mostram porcentagem semelhante à de ler numerais. Comparando com o resultado do Teste Inicial, pode-se ver que o aumento é ainda mais significativo, pois a maioria apresenta zero por cento de acertos por ocasião de sua aplicação, com exceção de P5 cujo resultado é da ordem de 70 por cento para numerais e de 60 por cento para palavras. No caso dos conjuntos de estímulos quantidade, todos os Ps apresentam 100 por cento de acertos, ainda que semelhantes conjuntos não tivessem feito parte do processo de ensino por exclusão e sete dos Ps tenham apresentado percentual de acerto entre 90 e 100 por cento (ver Figura 2).

Os dados sobre leitura e escrita de palavras são consistentes com os obtidos por d'Oliveira \& Matos (1993), Medeiros e cols. (2004), Melchiori, Sousa \& de Rose (1992) e Sidman (1971). Dos três ${ }^{9}$ comportamentos ensinados, leitura de palavras é o que se apresenta com maior variabilidade, seguida por numerais. A porcentagem de acertos de números está situada no valor mais alto, ou seja, 100 por cento para todos os Ps.

Os Ps 1, 2, 3 e 4 aprenderam com mais facilidade números, vistos à esquerda da Figura 3 . Todas as porcentagens das sessões finais dos Pós-T localizam-se no valor mais alto da escala (próximas de 100) dos gráficos quando comparada com as porcentagens dos Pré-T. Os dados mostram ainda que, à medida que o procedimento se desenvolvia, os Ps apresentavam quantidades maiores de acertos indicada pelo crescimento contínuo das curvas de cada um dos Ps. O mesmo processo, apresentado de outra forma, pode ser visto na parte inferior da Figura 10 . Nela, nota-se um decréscimo gradual no número médio de sessões realizadas. Esse processo, denominado de learning set (disposição para aprender). é comentado por Catania (1999), ao referir-se a um experimento com macacos realizado por Harlow, em 1949, em que "ao longo dos blocos sucessivos, o responder correto subiu mais e mais rapidamente durante as tentativas (...) em outras palavras, quanto mais problemas o macaco houvesse dominado, tanto mais rapidamente ele dominava cada novo problema” (p. 170). Os dados relativos à leitura de palavras dos mesmos Ps encontram-se na parte central da Figura 3. Pode-se ver que a variabilidade é mais acentuada quando comparada com a variabilidade da identificação de números e numerais. Ainda assim, a característica de um processo contínuo de aquisição (aumento progressivo do número de acertos) mostra-se presente com exceção de P3. O agrupa- 
mento de números, numerais e palavras, vistos à direita de cada gráfico, apresentados juntos na situação de teste, foi lido (rCD) com alta porcentagem de acertos por $\mathrm{P} 4$ e com porcentagem mais baixa por P3, contudo os Ps 1 e 2 não leram as classes de estímulos agrupadas provavelmente porque não atingiram os critérios de desempenho estipulados para passar de uma exclusão a outra.

Os dados sobre o desempenho dos Ps 5, 6 e 7, apresentados na Figura 4, dos Ps 8, 9 e 10, apresentados na Figura 5 e dos Ps 11, 12 e 13, apresentados na Figura 6, indicam que esses Ps aprenderam ambas as relações (de ler números e numerais e de leitura de palavras), com porcentagens próximas de 100 por cento nas sessões finais. Na etapa de agrupamento, responderam com alta porcentagem de acertos às novas configurações, mostrando, dessa forma, comportamentos emergentes.

A Figura 7 mostra a porcentagem de leitura de unidades de agrupamento, em que se verifica que a leitura das unidades compostas foi mais fácil para os agrupamentos de números e palavras (gráfico superior direito) do que de numerais e palavras (gráfico inferior direito). Isso pode ser verificado no gráfico superior direito, onde há maior concentração (oito valores) de pontos percentuais acima da linha divisória de 90 por cento, enquanto que no agrupamento de numerais e palavras há cinco valores de pontos percentuais acima da linha divisória de 90 por cento. Isso talvez se deva ao fato de que números mais do que numerais fazem parte mais cedo na vida das crianças. Essa maior dificuldade para a leitura de numerais agrupados com palavras provavelmente se deva ao fato de que os numerais exigem leitura de sílabas não familiares (ditongos, como em dois, seis, oito, consoantes seguidas, como em três, quatro, cinco etc.) que, em geral, são aprendidas mais tarde na vida escolar no processo de aprendizagem de leitura.

Alguns Ps apresentaram mais dificuldades na leitura de unidades compostas por palavras e numerais, mesmo assim todos eles responderam com alta porcentagem de acertos no teste de equivalência apresentado na Figura 8. O teste de equivalência de agrupamento, cujos dados encontram-se na Figura 9, mostra claramente que os estímulos compostos (números + figuras e numerais + palavras, como ilustrado na letra c da Figura 1) são também equivalentes, pois controlaram com alta porcentagem de acertos a leitura dos Ps.

Afinal, que tipo de contribuição este procedimento pode oferecer? Mostra, a princípio, que é possível ensinar separadamente os repertórios matemáticos (a identificação de números e numerais) e leitura de palavras e de testá-los de forma conjunta. Mostra, também, que essa maneira de ensinar produziu a emergência de leitura de frases curtas compostas de números e palavras e de numerais e palavras de ensino alternadamente dentro de um mesmo procedimento. Por exemplo, ensinou-se alternadamente os números 1,2 e 3 e as palavras cama, mago e foca e os Ps mostraram-se capazes de ler não apenas o agrupamento desses estímulos como também de ler no plural palavras de ensino no singular. Por exemplo, 2 camas (foram ensinados 2 e cama - ver ilustração na letra b da Figura 1). Mostraram-se, também, capazes de ler formas numéricas diferentes daquelas ensinadas. Por exemplo, foi ensinado "dois" e, no teste de agrupamento, emergiu a leitura da forma "duas". O mesmo ocorreu com o numeral ensinado "um" que, no teste de agrupamento, os Ps leram também a derivação "uma”. O teste de equivalência de agrupamento mostra que os Ps leram as unidades agrupadas com significado.

O ensino de palavras (d'Oliveira \& Matos, 1993; Matos e cols., 2002; Medeiros e cols., 1997; Melchiori e cols., 1992; Sidman \& Cresson, 1973) e de frases (Bastos, 2004) por meio do procedimento de exclusão mostra resultados que são consistentes com os obtidos por uma grande maioria de pesquisadores da área de equivalência de estímulos. Os resultados mais consistentes tem sido aqueles obtidos quando se controla a posição das sílabas componentes das palavras, ora sendo reforçadas na primeira, ora na segunda posição (d’Oliveira \& Matos, 1993; Medeiros e cols., 2004). O ensino de números, semelhante ao de palavras, tem se mostrado promissor na medida em que os resultados têm levado os pesquisadores a identificar em mecanismos semelhantes na produção de classes de ensino e de generalização (Carmo, 1997, 2002; Drachenberg, 1973, 1990; Monteiro \& Medeiros, 2002). Contudo, pouco se sabe a respeito do ensino conjunto de palavras e números, pois não se localizou qualquer estudo que descrevesse semelhante procedimento.

O estudo foi realizado com crianças de $1^{a}$ série que são expostas a procedimentos de ensino de palavras e números, ensinados regularmente nas séries iniciais. Os resultados obtidos podem ser consequiência também do procedimento de ensino da professora. O delineamento, como foi realizado, não permite separar os efeitos das contingências experimentais dos efeitos das contingências de ensino utilizadas pelas professoras. Para verificar se, de fato, ocorre esse tipo de influên- 
cia, o próximo experimento foi planejado para ser realizado também com um grupo da pré-escola, onde o ensino de leitura e de números é incipiente. Os resultados desse procedimento poderão indicar com mais precisão a natureza dos resultados.

\section{REFERÊNCIAS}

Bastos, E. C. M (2004). Ensino de leitura de frases com compreensão a alunos de séries iniciais de uma escola pública de Belém. Dissertação de Mestrado não-publicada, Programa de Pós-Graduação em Teoria e Pesquisa do Comportamento, Universidade Federal do Pará, Belém.

Bush, K. M., Sidman, M., \& de Rose, T. (1989). Contextual control of emergent equivalence. Journal of the Experimental Analysis of Behavior, 51(1), 29-45.

Carmo, J. S. (1997). Aquisição do conceito de número em crianças pré-escolares através do ensino de relações condicionais e generalização. Dissertação de Mestrado não-publicada, Curso de Mestrado em Psicologia: Teoria e Pesquisa do Comportamento, Universidade Federal do Pará, Belém.

Carmo, J. S. (2002). Comportamento conceitual numérico: Um modelo de rede de relações equivalentes. Tese de Doutorado não-publicada, Programa de Pós Graduação em Educação Especial, Universidade Federal de São Carlos.

Catania, A. C. (1999). Aprendizagem: Comportamento, linguagem e cognição (4a ed) (D. G. de Souza, Trad.). Porto Alegre: Artes Médicas.

de Rose, J. C., Souza, D. G., Rossito, A. L., \& Rose, T. M. S. (1992). Stimulus, equivalence and generalization in reading after matching-to-sample by exclusion. Em S. C. Hayes \& L. J. Hayes (Orgs.), Understanding verbal relations (p. 69-82). Reno: Context Press.

de Rose, J. C., Garotti, M. F., \& Ribeiro, I. G. (1992). Transferência de funções discriminativas em classes de estímulos equivalentes. Psicologia: Teoria e Pesquisa, 8(1), 43-65.

Dixon, L. S. (1977). The nature of control by spoken words over visual stimulus selection. Journal of the Experimental Analysis of Behavior, 27, 433-442.

d'Oliveira, M. H., \& Matos, M. A. (1993). Controle discriminativo na aquisição da leitura: Efeito da repetição e variação na posição das sílabas e letras. Temas em Psicologia, 2, 99-108.

Drachenberg, H. B. (1973). Programação das etapas que levam à modificação gradual no controle de certos aspectos de um estímulo para o outro (fading) na situação "escolha de acordo com o modelo”. Ciência e Cultura, 25(1), 44-53.

Drachenberg, H. B. (1990). Aquisição do conceito de quantidade: Programação de um procedimento de "escolha conforme o modelo" para crianças. Assis, SP: FCLA/ HUCITEC.

Gast, D. L., VanBiervliet, A., \& Spradlin, J. E. (1979). Teaching number-word equivalences: A study of transfer. American Journal of Mental Deficiency, 83, 524-527.

Goyos, A. C. N., \& Almeida, J. C. (1996). Mestre (Versão 1.0) [Software]. São Carlos, SP: Mestre Software.

Green, G. (1993). Stimulus control technology for teaching number/quantity equivalences. Em Victoria Autistic Childrens \& Adults Association (Org.), Proceedings of the 1992 Conference of the National Association for Autism (p. 51-63). Melbourne, Australia.

Hanna, E. S., Souza, D. G., de Rose, J. C., Santos, L. G., Fonseca, M. L., Horowitz, D. B., Carvalho, G. P., Sallorenzo, L. H., Balduíno, L. H., \& Veiga, H. (1993). Treino de cópia com resposta construída e o desempenho em ditado II: Efeitos dependentes do nível de generalização na linha de base de leitura [Resumo]. Em Sociedade Brasileira de Psicologia (Org.), Resumos de comunicações científicas, XXIII Reunião Anual de Psicologia (p. 305). Ribeirão Preto: SBP.

Kahhale, E. M. S. P. (1993). Comportamento matemático: Formação e ampliação do conceito de quantidade e relações de equivalência. Tese de doutorado não-publicada, Curso de Doutorado em Psicologia Experimental, Universidade de São Paulo.

Kennedy, C. H., \& Serna, L. A. (1995). Emergent relational responding upon quantity and equivalence. Psychological Record, 45, 241-248.

Mackay, H. A. (1985). Stimulus equivalence in rudimentary reading and spelling. Analysis and Intervention in Developmental Disabilities, 5, 373-387.

Matos, M. A., Peres, W., Hübner, M. M., \& Malheiros, R. H. S. (1997). Oralização e cópia: Efeitos sobre a aquisição de leitura generalizada recombinativa. Temas em Psicologia, 1, 47-64.

Matos, M. A., Hubner, M. M., Serra, V. R. B. P., Basaglia, A. E., \& Avanzi, A. L. (2002). Redes de relações condicionais e leitura recombinativa: Pesquisando o ensinar a ler. Arquivos Brasileiros de Psicologia, 54(3), 284-303.

Medeiros, J. G., Monteiro, G., \& Silva, K. Z. (1997). O ensino da leitura e escrita a um participante adulto. Temas em Psicologia, $1,65-78$.

Medeiros, J. G., Fernandes, A. R., Pimentel, R., \& Simone, A. C. S. (2004). A função da nomeação oral sobre comportamentos emergentes de leitura e escrita ensinados por computador. Estudos de Psicologia (Natal), 9(2), 249-258.

Medeiros, J. G., Vettorazzi, A., Kliemann, A., Kurban, L., \& Matheus, M. S. (2007). Emergência conjunta dos comportamentos de ler e escrever palavras e identificar números após o ensino em separado destes repertórios. Psicologia, Ciência e Profissão, 27, 4-21.

Melchiori, L. E., Souza, D. G., \& de Rose, J. C. C. (1992). Aprendizagem de leitura por meio de um procedimento de discriminação sem erros (exclusão): Uma replicação com pré-escolares. Psicologia: Teoria e Pesquisa, 8(1), 101-111.

Monteiro, G., \& Medeiros, J. G. (2002). A contagem oral como pré-requisito para a aquisição do conceito de número com crianças pré-escolares. Estudos de Psicologia (Natal), 7(1), 7390.

Prado, P. S. T. (1995). O conceito de número: Uma análise na perspectiva do paradigma de rede de relações. Dissertação de Mestrado não-publicada, Programa de Pós-Graduação em Educação Especial, Universidade Federal de São Carlos.

Sidman, M. (1971). Reading and auditory-visual equivalences. Journal of Speech and Hearing Research, 14, 5-13.

Sidman, M., \& Cresson, O. (1973). Reading and crossmodal transfer of stimulus equivalencies in severe mental retardation. American Journal of Mental Deficiency, 77, 515-523. 
Sidman, M. (1990). Equivalence relations: Where do they come from? Em D. E. Blackman \& H. Lejeune (Orgs.), Behaviour analysis in theory and practice: Contributions and controversies (p. 93-114). Brighton, UK: Erlbaum.

Souza, D. G., \& de Rose, J. C. (1997). Transferência de controle de estímulos de figuras para texto no desenvolvimento de leitura generalizada. Temas em Psicologia, 1, 33-46.

\section{Notas:}

1 Artigo derivado do Projeto PIBIC/CNPq 2005-2006, com apoio do CNPq ao autor principal através de bolsa de produtividade em pesquisa (Processo n. 303036/2004-4) e de apoio financeiro do Edital Universal (Processo n. 47.5932/2004-8).

2 O repertório matemático ensinado foi denominado de identificar ao invés de conceituar números, pois o procedimento garantiu a aquisição de algumas das relações conforme estão descritas em Monteiro e Medeiros (2002, p. 73), sendo ensinado-lhes a identificar os algarismos arábicos de 1 a 9 e os numerais cardinais correspondentes.

3 Número colocado ao lado de uma palavra formando uma classe de estímulos composta por duas unidades.

4 Números (1, 2, 3...); numerais (um, dois, três...) e quantidades (o, oo, ooo...).

5 Ver Figura 2, parte inferior esquerda.

6 Eram apresentadas, em ordem aleatória, as letras que compunham os estímulos modelos (A ou C) a serem montados, além de outras letras que não faziam parte dos respectivos estímulos.

7 Para garantir a concordância entre numerais e palavras, foi necessário apresentar palavras no plural além daquelas ensinadas (p. ex: bola [bolas], mago [magos], tatu [tatus]); um [uma], dois [duas], em que uma e duas foram acrescentados. (Ver na Tabela 1 a relação completa.)

8 Embora as palavras tivessem sido ensinadas no singular, no teste de AG, quando necessário, elas foram apresentadas no plural.

$9 \quad$ Nomear quantidade foi apenas testado antes de iniciar o procedimento, mas não foi ensinado.

\section{Sobre os autores:}

José Gonçalves Medeiros: Professor doutor, orientador do Programa de Pós-Graduação em Psicologia (Cursos de Mestrado e Doutorado) da Universidade Federal de Santa Catarina. Líder do Grupo de Pesquisa "Investigação em Linguagem e Comportamento Verbal” do Diretório de Grupos de Pesquisa do Brasil. Bolsista de Produtividade em Pesquisa, nível 2 do CNPq. Tesoureiro da Sociedade Brasileira de Psicologia. Membro do GT da ANPEPP “Investigações Conceituais e Aplicadas em Análise do Comportamento”.

Igor Schütz dos Santos: Graduando do Curso de Psicologia da Universidade Federal de Santa Catarina. Bolsista de Iniciação Científica (IC) / PIBIC e participante do Diretório dos Grupos de Pesquisa do Brasil.

Adriana Garcia Stefani: Graduando do Curso de Psicologia da Universidade Federal de Santa Catarina. Bolsista de Iniciação Científica (IC) do CNPq e participante do Diretório dos Grupos de Pesquisa do Brasil.

Vinicius Linhares Martins: Graduando do Curso de Psicologia da Universidade Federal de Santa Catarina. Bolsista de Iniciação Científica (IC) / PIBIC e participante do Diretório dos Grupos de Pesquisa do Brasil.

Endereço para correspondência: José Gonçalves Medeiros - Caixa Postal 5060 - 88040-970- Florianópolis/SC - Endereço eletrônico: jose.medeiros@pesquisador.cnpq.br 